\title{
Thailand: Selected Issues
}

This Selected Issues paper for Thailand was prepared by a staff team of the International Monetary Fund as background documentation for the periodic consultation with the member country. It is based on the information available at the time it was completed on May 2, 2008. The views expressed in this document are those of the staff team and do not necessarily reflect the views of the government of Thailand or the Executive Board of the IMF.

The policy of publication of staff reports and other documents by the IMF allows for the deletion of market-sensitive information.

Copies of this report are available to the public from

International Monetary Fund $\bullet$ Publication Services

700 19th Street, N.W. • Washington, D.C. 20431

Telephone: (202) 623-7430 • Telefax: (202) 623-7201

E-mail: publications@imf.org • Internet: http://www.imf.org

Price: $\$ 18.00$ a copy

\section{International Monetary Fund Washington, D.C.}





\section{INTERNATIONAL MONETARY FUND}

\section{THAILAND}

\section{Selected Issues}

Prepared by Shekhar Aiyar, Sanjay Kalra, Ivan Tchakarov (all APD), and Jeanne Gobat (MCM)

Approved by the Asia and Pacific Department

May 2, 2008

Contents

I. Much Ado About Nothing? Estimating the Impact of a U.S. Slowdown on Thai Growth .3

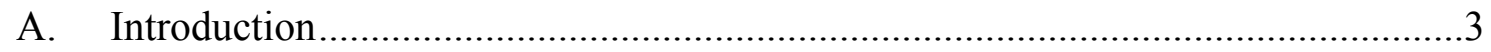

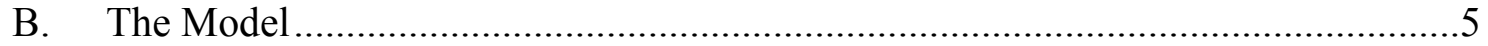

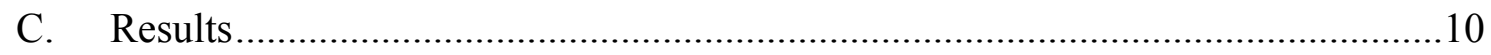

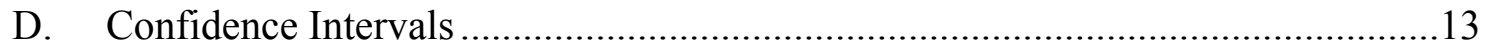

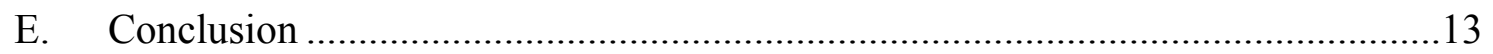

Figures

1. Data Used for Estimation ................................................................................... 15

2. Responses to a 1 Percent Slowdown in U.S. Growth ............................................. 16

3. Robustness - Confidence Intervals of GDP Growth Responses .................................17

Table

1. Model Parameter Estimation Results...........................................................................18

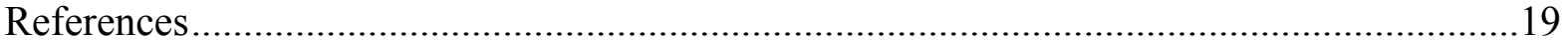

II. Global Volatility, Exchange Rates in Asia and the Thai Foreign Exchange Market .....20

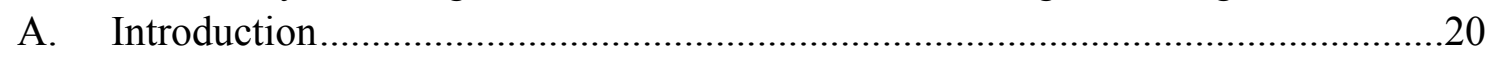

B. Foreign Exchange Returns and Volatility: Empirical Analysis..........................21

C. The Foreign Exchange Market in Thailand .......................................................23

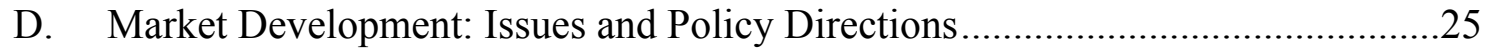


Figures

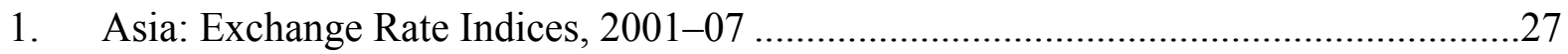

2. Asia: Exchange Rate Indices Daily Returns, 2001-07 .............................................28

3. Asia: Exchange Rate Indices, Squared Daily Returns, 2001-07 .................................29

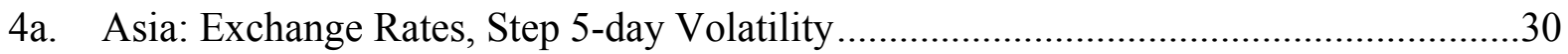

4b. Asia: Exchange Rates, Step 23-day Volatility, 2001-07...........................................31

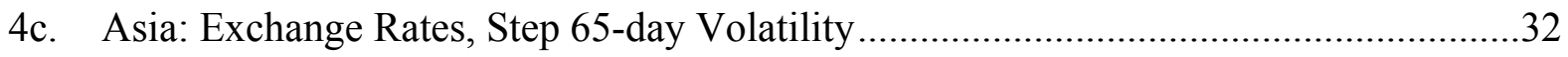

4d. Asia: Exchange Rates, Step 261-day Volatility ........................................................33

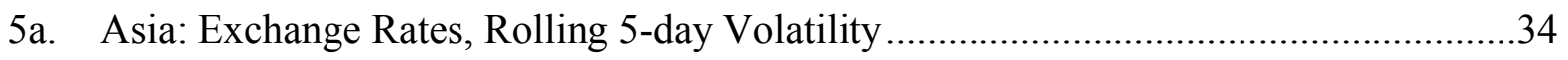

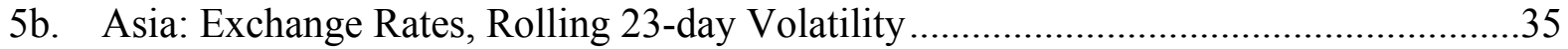

5c. Asia: Exchange Rates, Rolling 65-day Volatility .......................................................36

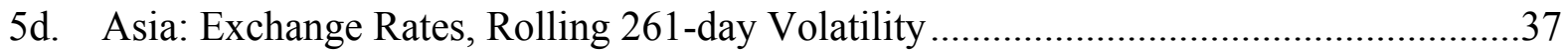

6. Size of Foreign Exchange Markets in Selected Emerging Market Countries ................38

Tables

1. Average Daily Bilateral Foreign Exchange Rate Regimes, Summary Statistics...........39

2. Volatility of Daily Foreign Exchange Returns (monthly average),

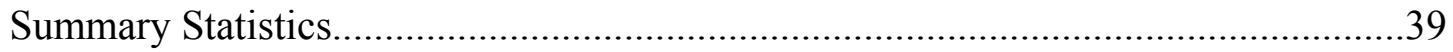

3. Correlation between Daily Return Volatility (Monthly Average) and VIX.................39

4. Liquidity Characteristics of Foreign Exchange Markets in Selected Emerging Market Countries

Appendix

References 


\section{Much Ado About Nothing? Estimating THE IMPACT OF A U.S. SLOWDOWN ON ThaI GrowTH ${ }^{1}$}

External demand has been the main driver of growth in Thailand in 2006 and 2007. However, recent IMF World Economic Outlook (WEO) projections indicate moderating foreign demand this year, with U.S. growth being revised downwards to reflect the turmoil in housing and credit markets, and high oil prices. While the share of Thai exports to the US has fallen in recent years, the US remains Thailand's largest export destination. We use a small structural model and Bayesian estimation to assess the possible impact of a U.S. slowdown on Thai growth. We find that a 1 percent slowdown in U.S. growth in 2008relative to the baseline forecast-could have an upper-bound impact on Thai GDP growth of 0.9 percentage points.

\section{A. Introduction}

1. Thailand is a very open economy, and as such, its domestic fortunes are strongly linked to external demand conditions. The share of trade in GDP has been increasing steadily over time, and stood at over 140 percent in 2006. Exports of goods and services accounted for about 74 percent of GDP. Moreover, over the last two years, Thai growth has been driven to a very large extent by net exports. The unsettled political situation and some market-unfriendly policy measures have weakened domestic demand,

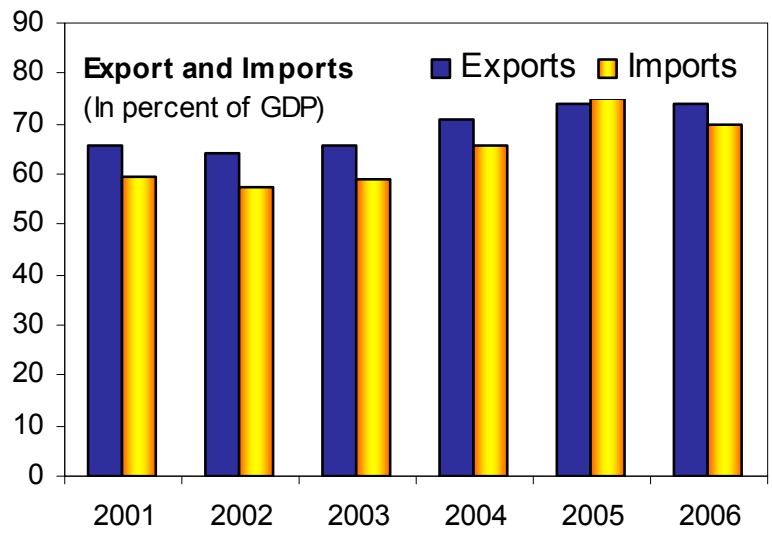
with the contribution of domestic investment to growth being negative for four out of six quarters since the beginning of 2006. The strong performance of net exports has therefore been the engine of growth.

\section{Net exports have performed} exceptionally well over the last two years. Partly, this is because depressed domestic demand has led to a fall in imports. Imports grew at an anemic 7 percent in 2006 and 6.4 percent in 2007 (H1), after registering average growth of about 14 percent over the previous five years. But it is also because of surging

\footnotetext{
${ }^{1}$ Prepared by Shekhar Aiyar and Ivan Tchakarov.
}

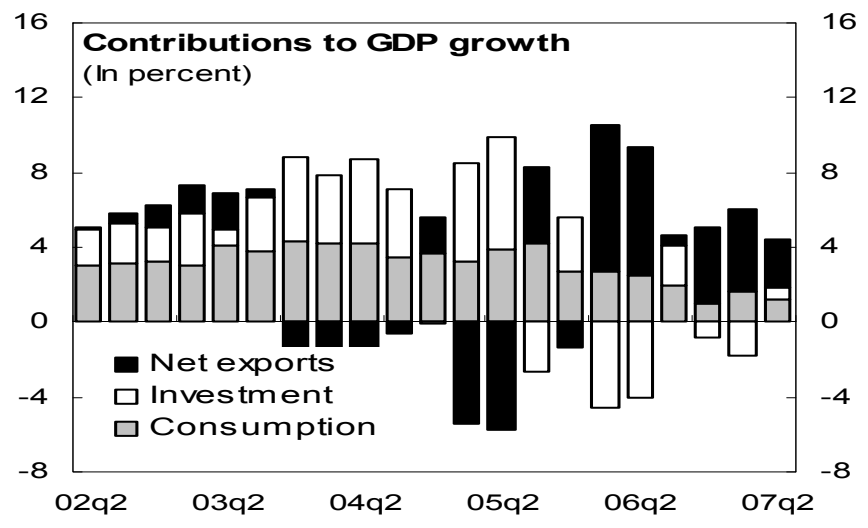


exports, which grew at 17.4 percent and 18.4 percent in 2006 and 2007 (H1) respectively, after registering average growth of about 10.5 percent over the previous five years.

\section{In these circumstances, any slowdown in external demand could have a}

potentially strong impact on the Thai economy. Thailand's most important export market is the US, accounting for 15 percent of Thai exports in 2006. Moreover, the correlation between U.S. growth and Thai exports, and between U.S. growth and Thai growth, has been positive over a long time period. ${ }^{2}$
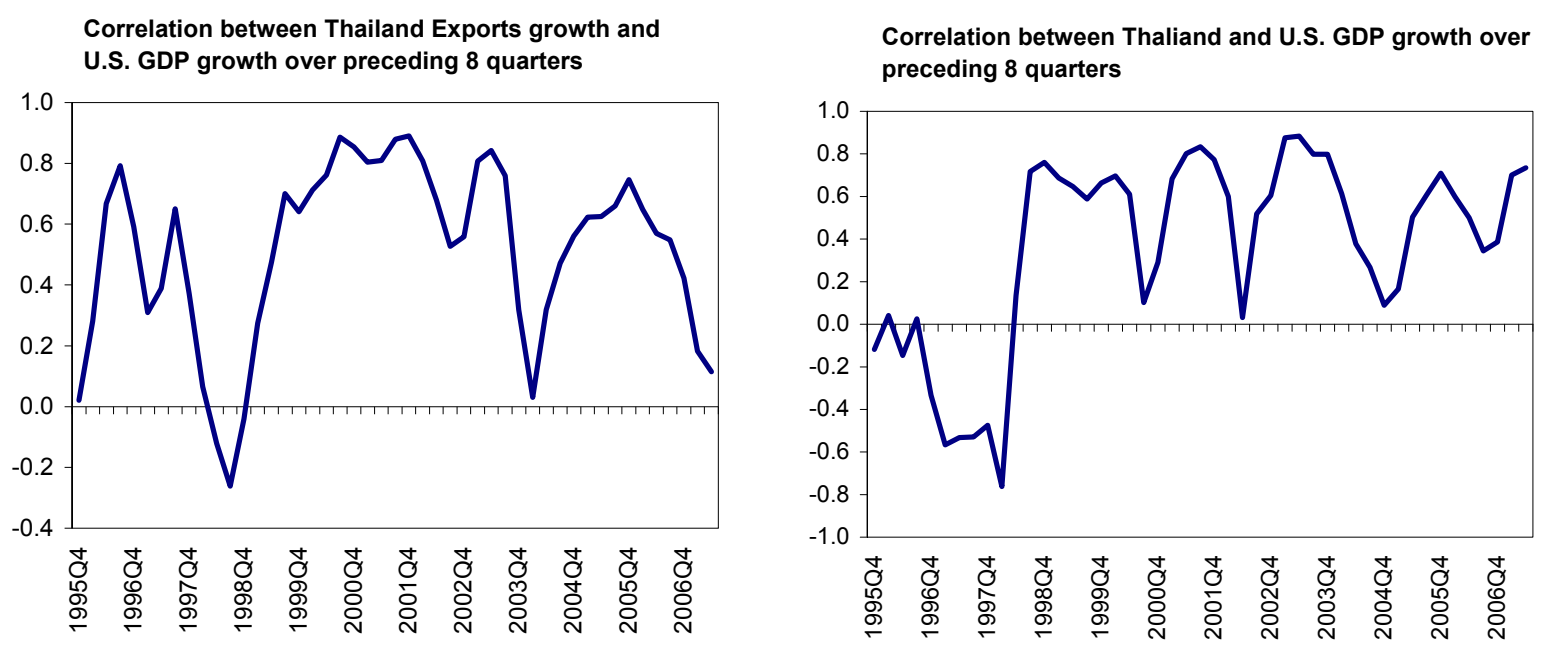

\section{There is a strong consensus that}

the US is headed toward a slowdown in economic growth, which may be exacerbated by the recent woes in the subprime mortgage market, in housing and credit markets more broadly, and by high oil prices. WEO forecasts suggest that growth in 2007 will fall to 1.9 percent from 2.9 percent the previous year, and remain at

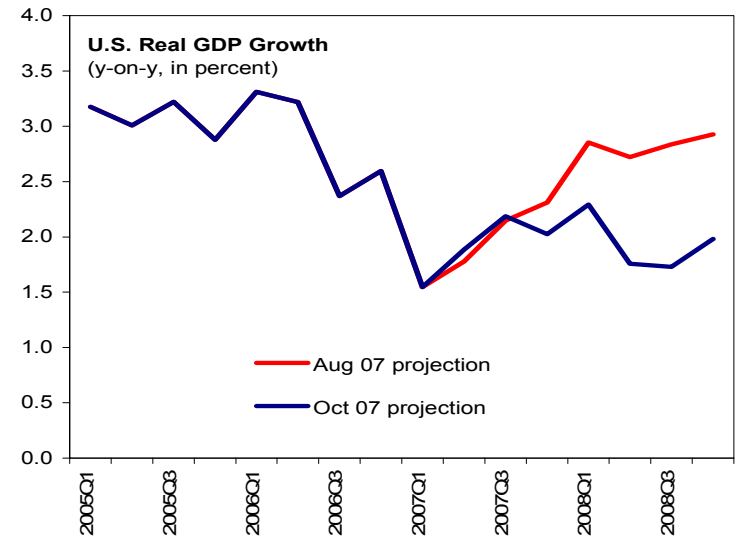

\footnotetext{
${ }^{2}$ Is there evidence of "decoupling"? Different data suggest different answers. On the one hand, the U.S. share of Thai exports has been declining steadily over time, with the trade shares of China, the Middle East, and other Asian countries rising. On the other hand, looking at the three preceding U.S. recessions - in 1990-91, 1995, and 2001 - it is evident that the largest impact on Thai growth and exports was in 2001. This is because the magnitude of the U.S. slowdown in 2001 was much larger than the earlier episodes, and because the collapse of the information technology bubble led to a sharp decline in imports of information processing equipment, in which Thailand (along with other Asian countries) has been increasingly specializing. Thus both the magnitude and the sectoral composition of a future U.S. slowdown would be relevant to the impact on Thailand.
} 
that depressed level in 2008. Moreover, forecasts of the U.S. economy have been getting more pessimistic over time, as illustrated by a comparison of August and October WEO projections.

5. The combination of a Thai economy in which net exports are the main engine of growth, and a slowdown in Thailand's largest trade partner presents an obvious challenge for the country. This paper contributes to the analysis of that challenge by estimating the impact of the projected U.S. slowdown on Thailand's economy in the context of a small general equilibrium model. We examine the response of a deviation in U.S. growth from the WEO baseline on Thai inflation, growth, exchange rates, and interest rates. We also examine the implications of the speed of the monetary policy response to the external demand shock. Bayesian estimation is used to parameterize the model, thereby allowing a balance of historical data and expert judgment to decide parameter values; we hope that this will be conducive to a more constructive policy dialogue.

6. The paper is organized as follows. Section B introduces the model we use and our priors for various parameters. Section $C$ briefly describes the estimation technique. Section D details our main results. Section E provides some confidence intervals for our analysis. The next section concludes.

\section{B. The Model}

7. The analysis is conducted using a small New Keynesian macroeconomic model with rational expectations, adapted from the framework developed by Berg, Karam and Laxton (2006) It blends the New Keynesian emphasis on nominal and real rigidities with the real business cycle tradition of dynamic stochastic general equilibrium modeling with rational expectations. Although such models can be derived explicitly from microeconomic foundations, in our framework, we employ only four structural macroeconomic equations, each of which is specified in a sufficiently general form to allow adaptive as well as rational expectations, and substantial inertia. While the equations contain several parameters of policy interest and generate detailed forecasts of important economic variables, the relatively small size of the model means that the process by which a particular set of parameters leads to a particular set of forecasts is transparent (compared, e.g., to the IMF's Global Economic Model $)^{3}$ Such models are at the center of policy-making analysis in many central banks in the world.

8. The model consists of two main sets of equations: the first describes the small Thailand economy, and the other, the US:

\footnotetext{
${ }^{3}$ See Berg, Karam and Laxton (2006) for further discussion of the philosophical underpinnings of the framework employed here.
} 


\section{Output gap equation}

Domestic output depends on the real interest rate, the real exchange rate, and demand in the rest of the world, represented by the US. Dynamics are added through past and future domestic output gaps:

$$
\operatorname{ygap}_{t}=\beta_{1} \operatorname{ygap}_{t-1}+\beta_{2} \operatorname{ygap}_{t+1}-\beta_{3}\left(R R_{t-1}-R R_{t-1}^{*}\right)+\beta_{4}\left(z_{t-1}-z_{t-1}^{*}\right)+\beta_{5} y_{u s g a p}^{*}+\varepsilon_{t}^{y}
$$

where ygap is the output gap, $R R$ is the real interest rate, $z$ (in logs) is the real exchange rate (measured so that an increase is a depreciation), and a '*' denotes an equilibrium value of a variable. The output gap is measured as the deviation, in percentage points, of actual output from a measure of the trend or equilibrium level of GDP (a positive number indicates that output is above trend). Finally, yusgap is a similarly measured output gap in the U.S. economy, included to capture spillover effects from U.S. demand to Thailand exports.

\section{Phillips curve}

Inflation depends on expected and lagged inflation, the output gap, and the exchange rate gap:

$$
\pi_{t}=\delta_{1} \pi_{t+4}^{4}+\left(1-\delta_{1}\right) \pi_{t-1}^{4}+\delta_{2} \operatorname{ygap}_{t-1}+\delta_{3}\left(z_{t}-z_{t-1}\right)+\varepsilon_{t}^{\pi}
$$

where $\pi_{t-1}^{4}$ is inflation over the last four quarters (four-quarter change in the CPI), and $\pi_{t+4}^{4}$ is the expected rate of inflation over the next four quarters. The lag term captures intrinsic inertia in the adjustment coming from sources other than expectations, such as adjustment costs or contracts.

\section{Exchange rate equation}

The exchange rate equation (in logs) imposes relative purchasing power or interest parity (IP), an arbitrage condition that says that real interest rates (on investments in different currencies) will be equalized across countries. A real exchange rate definition is used to write the conventional IP condition as a real IP condition as follows:

$$
z_{t}=z_{t+1}^{e}-\left(R R_{t}-R R_{t}^{U S}\right) / 4+\varepsilon_{t}^{z}
$$

where $R R_{t}^{U S}$ is the U.S. real interest rate. As before, $R R_{t}$ is the real policy interest rate and $z_{t}$ is the real exchange rate. Thus, any deviation of interest rates from equilibrium, either at home or abroad, would result in the exchange rate deviating from equilibrium, unless such rate deviations were identical. Any other movement in exchange rates is captured in the residual in the exchange rate equation, which can be thought of as a temporary shock to the 
risk premium. We also allow, but do not impose, model-consistent expectations for the exchange rate (i.e., $\left.\delta_{z} \neq 1\right)$ :

$$
z_{t+1}^{e}=\delta_{z} z_{t+1}+\left(1-\delta_{z}\right) z_{t-1}
$$

\section{Monetary policy rule}

The monetary policy reaction function is a variant of the Taylor rule - a forward-looking rule because interest rates are set as a function of expected future inflation $\left(\pi_{t+4}^{4}-\pi_{t+4}^{*}\right)$ as well as the output gap ygap.When these variables are zero, interest rates are set to "normal" levels $\left(R R_{t}^{*}+\pi_{t}^{4}\right)$. As is standard in reaction functions, we allow for "smoothing" in rate setting by introducing a lag term. The policy instrument is a short-term nominal interest rate and the central bank sets this instrument to anchor inflation to a target level, $\pi *$, over time:

$$
R S_{t}=\alpha_{1} R S_{t-1}+\left(1-\alpha_{1}\right)\left(R R_{t}^{*}+\pi_{t}^{4}+\alpha_{2}\left(\pi_{t+4}^{4}-\pi_{t+4}^{*}\right)+\alpha_{3} \operatorname{ygap}_{t}+\varepsilon_{t}^{R S}\right.
$$

\section{The Rest of the world (US)}

The rest of the world is represented by the U.S. economy. The behavioral equations are similar but without the world influences.

\section{Output gap}

$$
\text { yusgap }_{t}=\beta_{1}^{u s} \text { yusgap }_{t-1}+\beta_{2}^{u s} \text { yusgap }_{t+1}-\beta_{3}^{u s}\left(\operatorname{RRus}_{t-1}-R R u s_{t-1}^{*}\right)+\varepsilon_{t}^{y u s}
$$

\section{Phillips curve}

$$
\pi u s_{t}=\delta_{1}^{u s} \pi u s_{t+4}^{4}+\left(1-\delta_{1}^{u s}\right) \pi u s_{t-1}^{4}+\delta_{2}^{u s} \operatorname{yusgap}_{t-1}+\varepsilon_{t}^{\pi u s}
$$

\section{Policy reaction rule}

$$
R S u s_{t}=\alpha_{1}^{u s} R S u s_{t-1}+\left(1-\alpha_{1}^{u s}\right)\left(R_{R u s_{t}^{*}}^{*} \pi u s_{t}^{4}+\alpha_{2}^{u s}\left(\pi u s_{t+4}^{4}-\pi u s_{t+4}^{*}\right)+\alpha_{3}^{u s} \operatorname{yusgap}_{t}+\varepsilon_{t}^{R S u s}\right.
$$

9. The model is estimated with Bayesian techniques. These are based on the influential work of Schorfheide (2000). Papers using a Bayesian approach in the estimation of open economy DSGE models include Lubik and Schorfheide (2003) and Justiniano and Preston (2004). There are several advantages of using Bayesian methods for inference in estimating macroeconomic models. For our purposes, we highlight the fact that because Bayesian methods seek to characterize the posterior distribution of the parameters, they facilitate an accurate assessment of all of the uncertainty surrounding the model's 
coefficients. Indeed, posterior inference provides us with posterior probability bands without having to assume, for instance, symmetry in these distributions. ${ }^{4}$ We briefly sketch our approach to inference, and the reader is referred to the above references for further details. Defining $\Theta$ as the parameter space, we wish to estimate the model parameters denoted by $\theta \subset \Theta$. Given a prior $p(\theta)$, the posterior density of the model parameters, $\theta$, is given by:

$$
\left.p\left(\theta \mid Y^{T}\right)=\frac{L\left(Y^{T} \mid \theta\right) p(\theta)}{\int L\left(Y^{T} \mid \theta\right) p(\theta) d \theta}\right)
$$

where $L\left(Y^{T} \mid \theta\right)$ is the likelihood conditional on observed data, $Y^{T}$. The likelihood function is computed under the assumption of normally distributed disturbances by combining the state-space representation implied by the solution of the linear rational expectations model and the Kalman filter. Our goal is to therefore characterize the posterior density of the parameters. To do so, we follow a two-step approach. In the first step, a numerical algorithm is used to find an initial guess of the posterior mode by combining the likelihood $L\left(Y^{T} \mid \theta\right)$ with the prior. The posterior mode obtained from this first step is used as the starting value $\left(\theta^{0}\right)$ of a multiple chain Random Walk Metropolis algorithm. This Markov Chain Monte Carlo (MCMC) method allows us to generate draws from the posterior density $p\left(\theta \mid Y^{T}\right)$. At each step $i$ of the Markov Chain, the proposal density is used to draw a new candidate parameter $\theta^{*} \propto N\left(\theta^{i}, c \Sigma\right)$. The new draw is then accepted with the following probability:

$$
\omega=\min \left\{1, \frac{L\left(Y^{T} \mid \theta^{*}\right) p\left(\theta^{*}\right)}{\int L\left(Y^{T} \mid \theta^{i}\right) p\left(\theta^{i}\right)}\right\} .
$$

If accepted, $\theta_{k}^{i+1}=\theta_{k}^{*}$, otherwise, $\theta_{k}^{i+1}=\theta_{k}^{i}$. The total number of iterations generated in this manner is 100,000 replications in this manner, and we discarded the first 50,000 iterations while monitoring the convergence of the generated draws using potential scale reduction factors and trace plots. The scaling constant for the variance covariance matrix, $c$, is chosen to attain a 30 percent acceptance rate. With the generated draws, point estimates of $\theta$ can be obtained from the simulated values by using various location measures, such as means or

\footnotetext{
${ }^{4}$ There are also clear advantages when it comes to model comparisons because the models are not required to be nested and numerical methods for the computation of the marginal likelihood permit constructing posterior model probabilities. These probabilities can in turn be used for model averaging, thereby producing parameter estimates that also explicitly incorporate model uncertainty. Furthermore, as emphasized by Smets and Wouters (2003), the use of Bayesian methods provides greater stability to optimization algorithms relative to maximum likelihood.
} 
medians. Similarly, measures of uncertainty follow from computing the percentiles of the draws.

10. To estimate the model, we use four key macroeconomic series for Thailand and three macroeconomic series for the US. For Thailand, we use the real GDP, headline CPI inflation rate, the nominal interest rate, and the real bilateral exchange rate. For the US, we use real GDP, headline CPI inflation rate, and the nominal interest rate. Since the model is written in gaps form, we construct exogenously the equilibrium values of the real GDP, the real interest rate, and the real exchange rate using a variant of the Hodrick Prescott filter. To avoid the crisis period, the sample period runs from 1999Q1 to 2007Q2. The data used for the estimation are presented in Figure 1.

\section{The priors are chosen to reflect general considerations of the appropriate model} dynamics $^{5}$ and our judgment about the Thai economy. A complete list of all priors used is provided in Table 1. Lags in the transmission mechanism of monetary policy imply that, in the output gap equations, there would be substantial inertia in the evolution of the output gap with only a small forward-looking component, and that the sum of $\beta_{3}$ and $\beta_{4}$ would be smaller than $\beta_{1}$. In relatively open economies such as Thailand, we would also expect that $\beta_{4}$ would be at least as big as $\beta_{3}$. Since the model does not explicitly account for trade, and to capture the importance of U.S. growth for the Thai economy, we allow for a direct, though relatively muted, impact of the U.S. economy on Thai output gap through $\beta_{5}$. In the Phillips curve, $\delta_{1}$ is a measure of the forward-looking component of inflationary expectations, and it would be decreasing function of the pervasiveness indexation in the economy. As an empirical matter, data from most countries are consistent with a $\delta_{1}$, significantly below 0.5 . The parameter $\delta_{2}$ also depends on the balance between adaptive and rational expectations in the economy, with more backward-looking behavior consistent with larger values of the parameter. Here again, we choose a value, 0.25 , that is consistent with data from many countries. The effect of the exchange rate on inflation, $\delta_{3}$, reflects the pass-through of imported goods prices to domestic inflation. This parameter would typically be an increasing function of the openness of the economy, while remaining considerably smaller than the import weight in the CPI basket. ${ }^{6}$ In the uncovered interest parity (UIP) condition, rational expectations would $\operatorname{set} \delta_{z}=1$, but we assume an intermediate value of 0.5 . For the interest rate responses to inflation and output gap, $\alpha_{2}$ and $\alpha_{3}$, we choose 1.5 and 0.5 , consistent with Thailand being an inflation targeting country with a balance between adaptive and rational expectations. In the monetary policy rule, a typical value for the interest rate smoothing

\footnotetext{
${ }^{5}$ For further details, see Berg and others, IMF Working Paper 06/81.

${ }^{6}$ Berg and others (2006) use 0.1 for a model calibrated to Canada and the US.
} 
parameter, $\alpha_{1}$, is between 0.5 and 1 , with 1 representing the fullest inertia in monetary policy. We choose a value of 0.5 . For the US, the main differences in the choice of priors reflect the assumption that Thailand is too small to affect the U.S. economy, and that the US is isolated from exchange rate shocks. Technically, this means that we assume a zero prior for the foreign output in the output gap equation, and a zero prior for the exchange rate in the output gap equation and the Phillips curve.

\section{Results}

12. The estimation produces a number of interesting results. Table 1 reports the posterior estimates of each parameter. Along with the posterior mean, we present the $5^{\text {th }}$ and $95^{\text {th }}$ percentiles for the posterior distributions, which serve to quantify the uncertainty surrounding these estimates. Most of the estimated parameters are in the ballpark of our priors' assumptions, but a number of the estimates deserve closer scrutiny. The parameter on lagged gap term in the output gap equation is estimated at 0.21 , significantly away from its prior mean of 0.7 , demonstrating that the Thai economy does not exhibit significant inertia. Moreover, even though that the sum of $\beta_{3}$ and $\beta_{4}$ is estimated to smaller than $\beta_{1}$, as expected, it is not that much so, suggesting only moderate lags in the transmission of monetary policy. This may be related to the fact that the estimated parameter on the lagged interest rate in the monetary policy rule is quite big at $0.84,{ }^{7}$ allowing the monetary authorities to effect smaller changes in the policy rate that induce larger effects on the real economy. This may be more relevant in an environment where such small changes engender expectations that the direction of monetary policy will persist. The estimated coefficient $\delta_{z}$ su ggests that quite adaptive expectations for the exchange rate $^{8}$.

\begin{tabular}{|lccc|}
\hline \multicolumn{4}{|c|}{ Thailand: Baseline Scenario } \\
\hline & 2007 & 2008 & 2009 \\
\hline GDP & 4.5 & 5.0 & 5.2 \\
Inflation & 2.3 & 3.5 & 3.0 \\
Exchange rate & 34.570 & 34.055 & 34.055 \\
\hline
\end{tabular}

\section{The model is solved initially so that the baseline forecast replicates staff baseline} projections over the medium term. Following solid growth of 5 percent in 2006, growth in the first half of 2007 slowed to 4.3 percent (year-on-year). Low confidence has battered domestic demand, and growth was supported exclusively by external demand. For the year, staff estimates growth at 4.5 percent. Going forward, 2008 growth is projected at 5 percent,

\footnotetext{
${ }^{7}$ Woodford (2001) argues that a high parameter value represents optimal policy inertia. A higher coefficient on the lagged interest rate term implies some persistence in interest rate changes. Thus a small move in interest rates today creates the expectation of further moves in future periods, therefore, allowing a small move today to have a relatively large impact on agents' behavior and creating a relatively swift transmission mechanism from monetary policy.

${ }^{8}$ Isard and Laxton (2000).
} 
accelerating to 5.2 percent in 2009. This forecast is based on the assumption of rotation of demand from external to domestic sources and, therefore, already takes into account some slowdown in the U.S. economy. ${ }^{9}$ The baseline projection for the US is based on the September U.S. desk forecast. Growth slows from 2.9 percent in 2006 to 2.25 percent in both 2007 and 2008.

14. Next, the model is used to evaluate the risk to the baseline scenario stemming from a slowdown in U.S. growth. The main advantage of the model is that it can serve to frame the analysis about the baseline forecast, risks to the forecast, appropriate responses to an external demand shock, and the dependence of the forecast and policy recommendations on various sorts of assumption about the functioning of the economy.

\section{We analyze two main risk scenarios, and estimate that output in Thailand may} decline by up to 0.9 percent relative to baseline. We shock the output gap equation in the US in such a way that 2008 U.S. GDP falls by 100 basis points from 2.25 percent to 1.25 percent. This is consistent with the lower end of the revised U.S. forecast of the October WEO, which lowers the point estimate for growth in 2008 to 1.9 percent, with 1.25 percent falling within the 90 percent confidence band. First, we assume that monetary policy in Thailand fails to anticipate initially the timing of the shock and does not respond to the external disturbance for two quarters. Only after that does monetary policy allow the policy rate to adjust downwards to the fall in Thai output. Second, we allow for an immediate (model-based) response of monetary policy to the fall in U.S. output:

- $\quad$ Delayed monetary policy response: the negative external demand shock directly affects Thai output, which bottoms in the second quarter of 2008. The annual impact on output is significant. GDP growth falls by 0.9 percentage points below the baseline in 2008, before recovering in 2009. Because of the presence of forwardlooking features in the model, output begins slowing down relative to baseline in the third quarter of 2007, even though the shock occurs only at the beginning of 2008. Declining output translates into lower inflation, while the UIP condition dictates that the real exchange rate appreciates, because foreign interest rates fall by more than domestic interest rates.

- Immediate monetary policy response: the impact on Thai output is still appreciable, with GDP growth falling 0.6 percentage points below baseline. Therefore, the accommodative response of monetary authorities helps mute the decline in output by

\footnotetext{
${ }^{9}$ Since the estimation and simulation of the model, staff has updated slightly upwards its baseline forecast for Thailand in 2008 and 2009. However, the main value of the exercise presented here is to measure the impact of a U.S. shock on Thailand relative to a baseline. Because of the linearity of the model, the results should be robust to a change in baseline.
} 
0.3 percent. The qualitative response of inflation and the exchange rate are similar to the previous case.

\section{However, the adverse impact on Thai output is likely to be smaller than}

suggested above. The model incorporates a number of assumptions that may amplify the negative impact on output. For example, it does not incorporate a fiscal policy response that could be used to rebalance growth from external to domestic sources. Nor does it incorporate a risk premium. ${ }^{10}$ Most importantly, since we employ a standard two-country framework in the assessment, there is an implicit assumption that the US is Thailand's only trade partner, which magnifies the estimated impact coefficient.

\section{To be more specific, the co-efficient which measures the impact of the U.S.} output gap on Thai GDP in the investment-savings curve equation will be biased upwards due to omitted variables. This bias is an increasing function of the correlation between the U.S. business cycle and the business cycle of Thailand's other trade partners. Ideally, we would like to estimate the output gap equation with not just the U.S. output gap on the right-hand side (RHS), but the output gap of every one of Thailand's trade partners, particularly important partners such as China, emerging Asia, the EU, and Japan. Assuming that there is a positive correlation between the business cycles of Thailand's various trade partners, our two-country model will yield an exaggerated co-efficient for the U.S. output gap, which picks up not only the impact of the U.S. economy but also of other, correlated trade partners. ${ }^{11}$

\section{A lower bound on the impact on Thai output is provided by weighting the} estimated impact co-efficient by the U.S. share of Thailand's exports. This is equivalent to assuming perfect correlation between the U.S. economy and Thailand's other trade partners (as opposed to the zero correlation assumed in the earlier estimate), so that the estimated parameter picks up the impact of a coincident slowdown in all of Thailand's trade

\footnotetext{
${ }^{10}$ The UIP condition could be augmented by a risk premium that may render the resulting exchange rate appreciation less sensitive to the interest rate differential, which in turn may dampen the fall in output growth.

${ }^{11}$ One way to think about this is to consider a world in which there is zero correlation between the U.S. economy's business cycle and those of China, the EU, and other Thai trade partners. In this world, our twocountry model would yield an unbiased estimate of the impact of the U.S. economy on Thailand, because the U.S. economy is orthogonal to other trade partners. Next, consider a world in which there is a positive correlation of unity between the U.S. economy and China, the EU etc. In this world, our two-country model estimate of the U.S. impact on Thailand would actually represent the impact of a slowdown in all of Thailand's trade partners, and thus be a considerable overestimate.
} 
partners, and hence needs to be adjusted. As noted earlier, although the US is Thailand's largest single trade partner, it accounts for only about 15 percent of Thai exports. Therefore, in this third scenario, the fall in Thai GDP is a modest 0.135 percentage points below baseline.

\section{Confidence Intervals}

19. Bayesian analysis can be used to construct confidence intervals for output responses. While the previous analysis was based on calibrating the model with the posterior means of the estimated parameters, the Bayesian analysis allows for a broader characterization of the output response. In particular, since we estimate a posterior distribution, we could also construct confidence intervals, depicting a range of possible values for the effect of foreign output on domestic output. In Figure 3, we show the confidence intervals of the output response in the immediate policy response scenario over the marginal distribution of particular parameters. For example, the first panel shows the 90 percent lower and upper bound of output response as $\alpha_{1}$, the coefficient measuring the aggressiveness of monetary policy to changes in inflation, ranges from its 5 percent level to its 95 percent level, while keeping all other parameters at their posterior mean.

20. We examine the confidence intervals for output for all estimated parameters, but for most of them, the resulting confidence intervals around the immediate policy response scenario are quite tight. This may be because a given parameter is very tightly estimated or because it has limited bearing on the dynamic responses of output. Therefore, we report only those confidence intervals that exhibit somewhat wider bands around the immediate policy response scenario.

\section{E. Conclusion}

21. This paper has parameterized a New Keynesian, general equilibrium model of the Thai and U.S. economy, and to thereby obtain an estimate of the impact of a U.S. slowdown on Thailand. By using a small structural model and by employing Bayesian updating in estimation, the paper attempts to keep the postulated economic mechanisms transparent and amenable to policy discussion, while allowing the parameters to reflect a balance between expert judgment and the historical record.

\section{So, to return to the title of this paper, are the fears of a U.S. slowdown simply} much ado about nothing? More precisely, is the likely impact on Thailand's growth prospects small enough to be dominated by domestic demand conditions? The answer is a qualified yes. While the impact is nontrivial, it is indeed small compared to the movements in domestic demand expected in 2008, as the country moves forward from a period of political turbulence and depressed investor confidence. We estimate that a slowdown in U.S. growth of 100 basis points relative to the baseline could have an upper-bound impact on Thai GDP 
growth of about 0.9 percentage points, and a lower-bound impact of 0.135 percentage points. Where exactly the impact lies between these two bounds depends on the correlation between the US and Thailand's other trade partners. The midpoint of the range is 0.52 percentage points. Moreover, a quicker monetary policy response could reduce any potential impact by 0.3 percentage points. 
Figure 1: Thailand. Data Used for Estimation
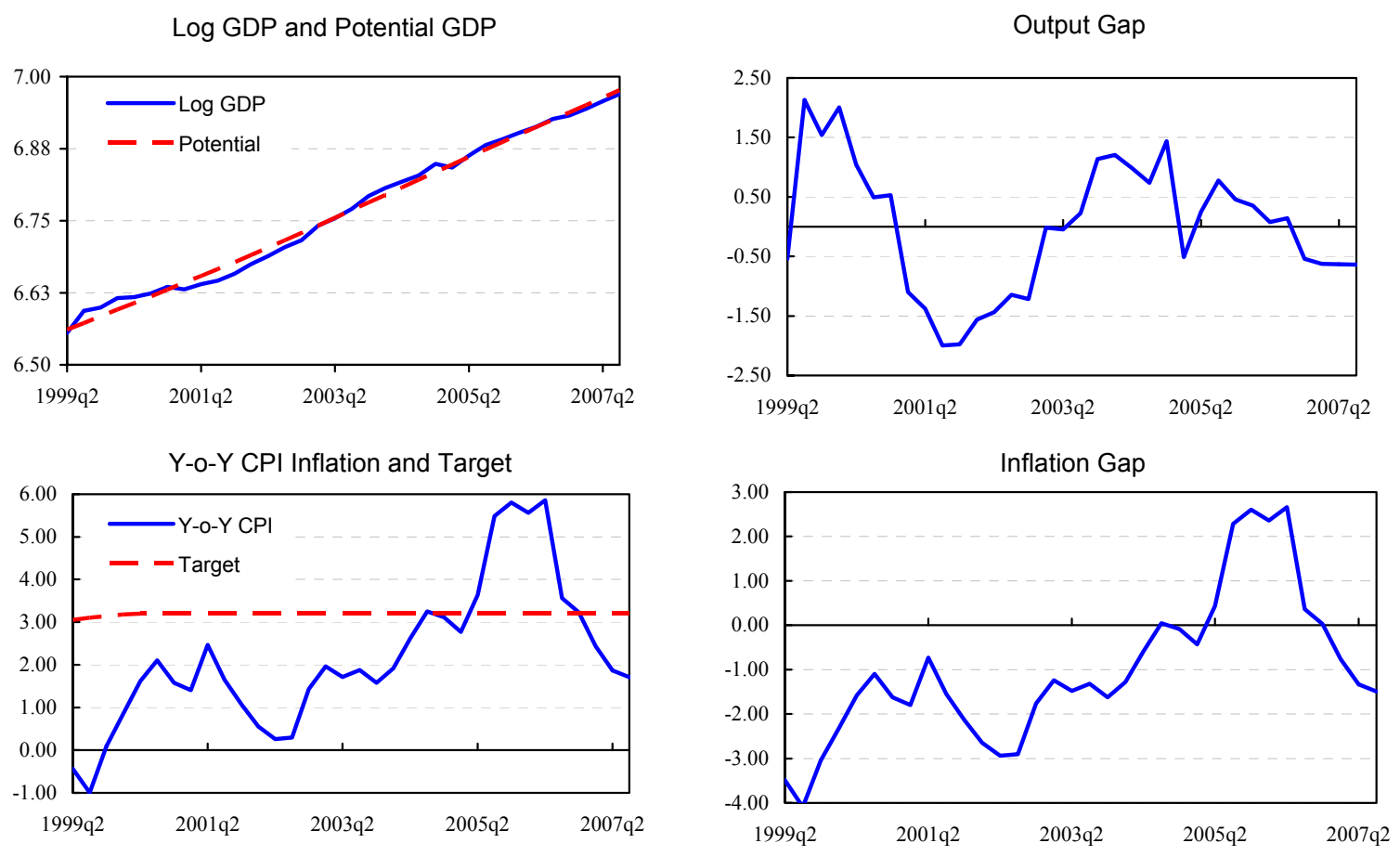

Real Short-tern Interest Rate and Equilibrium
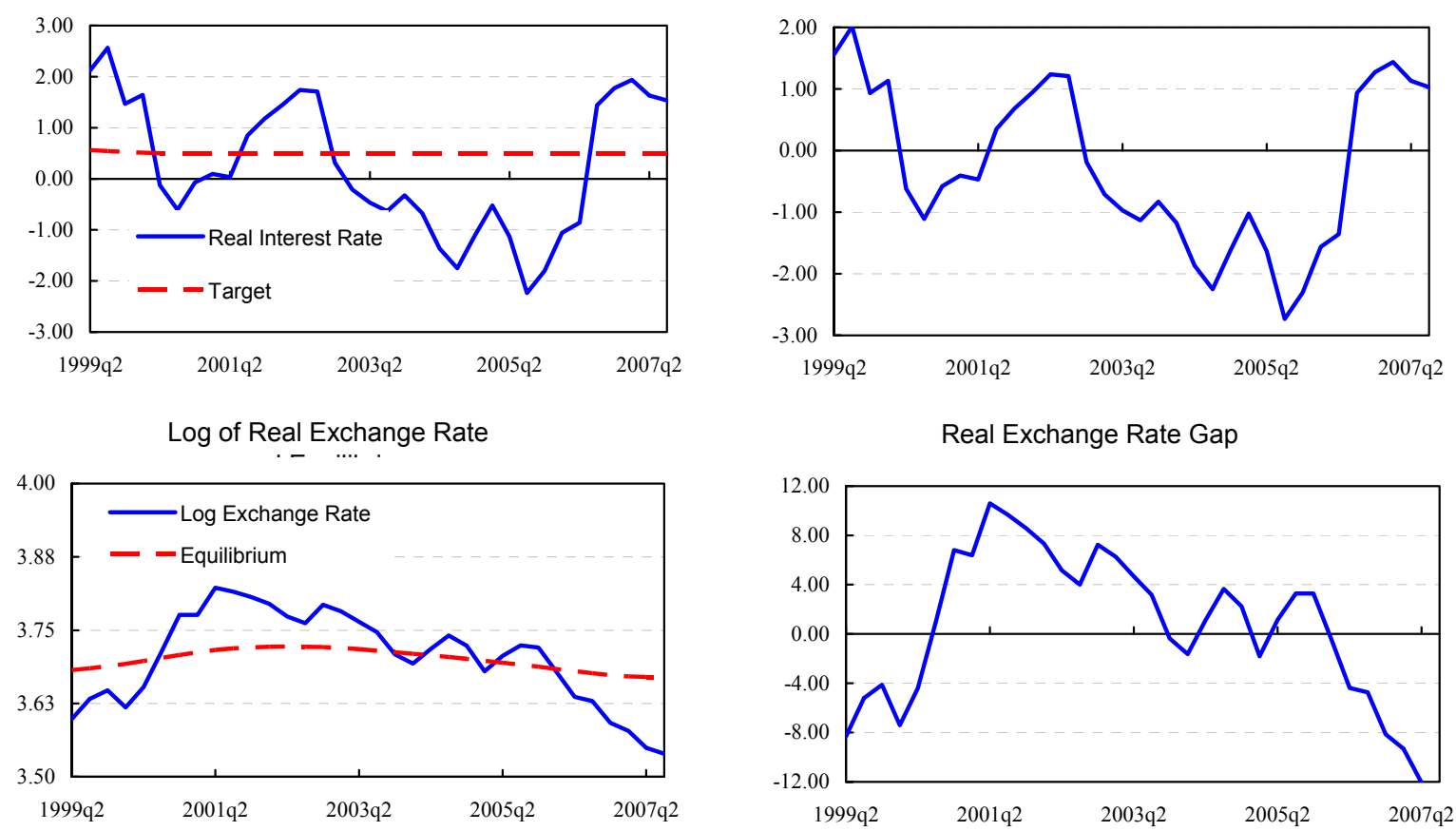

Source: IMF staff estimates. 
Figure 2: Thailand. Responses to a 1 percent Slowdown in U.S. Growth
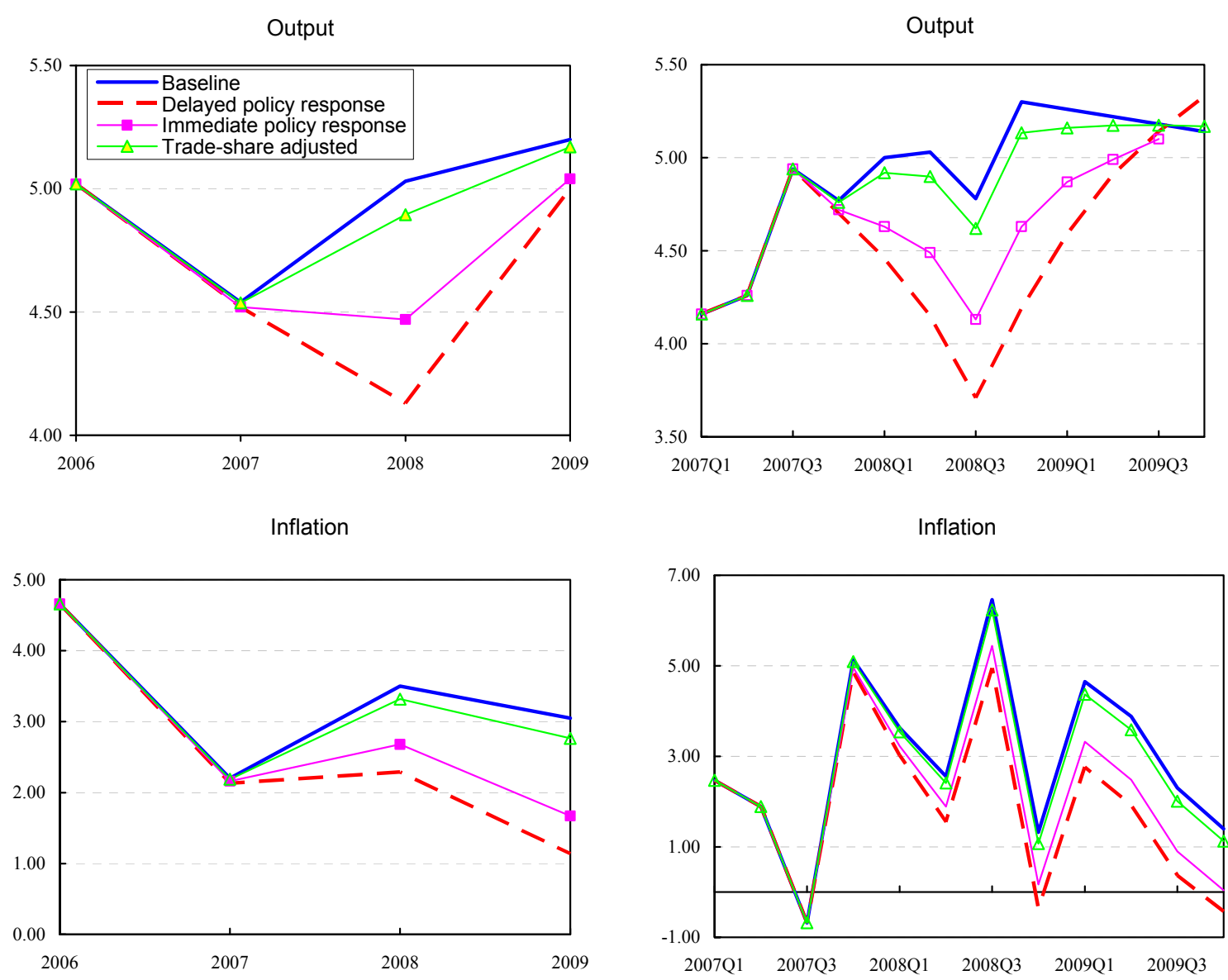

Exchange Rate
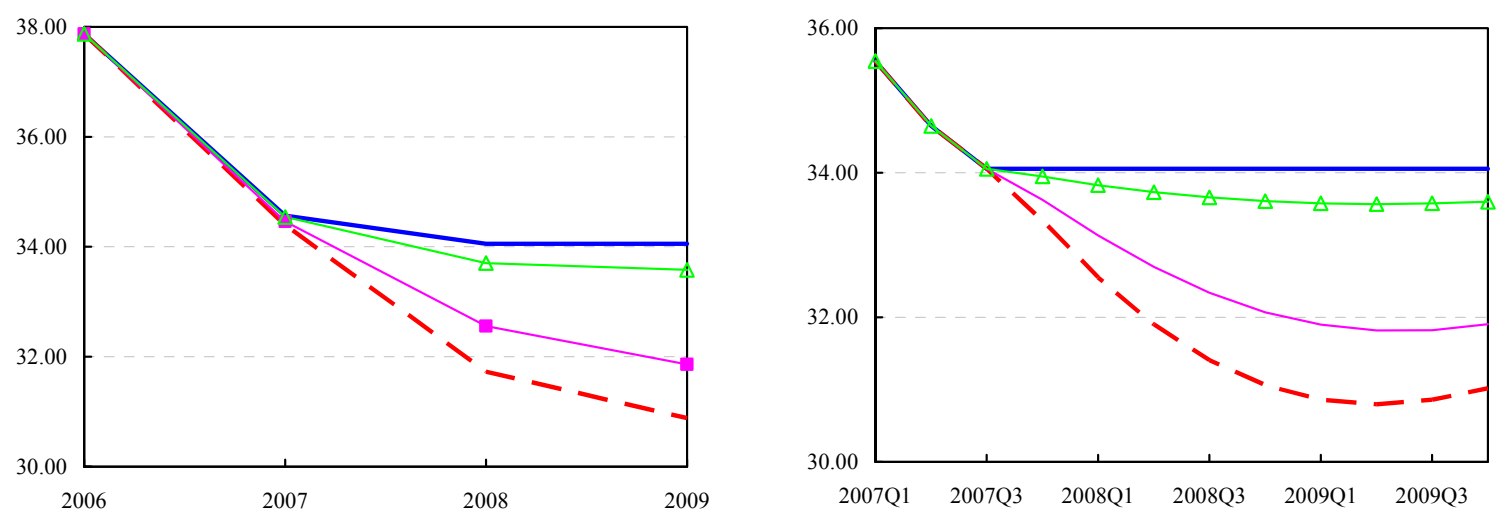

Source: Authors' calculations.

Note: This figure depicts the dynamic responses of Thai output to a negative 1 percent shock to U.S. output under different scenarios. 


\section{Figure 3: Robustness - Confidence Intervals of GDP Growth Responses}

Response over marginal distribution of alpha 1

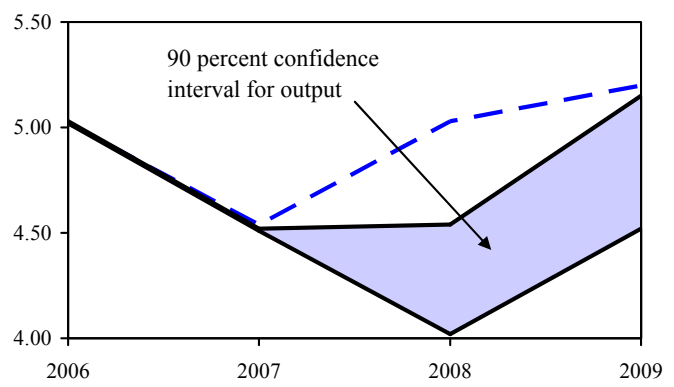

Response over marginal distribution of beta 1

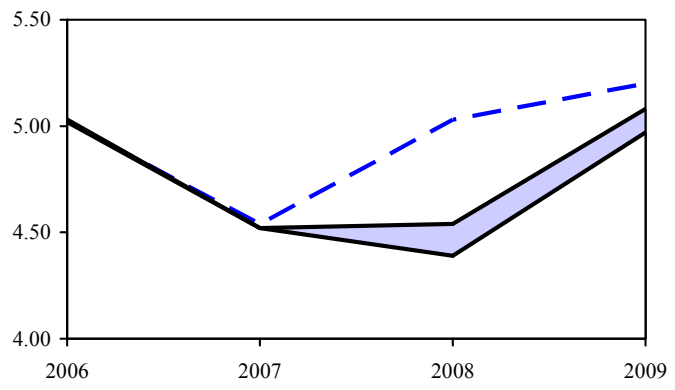

Response over marginal distribution of beta 4

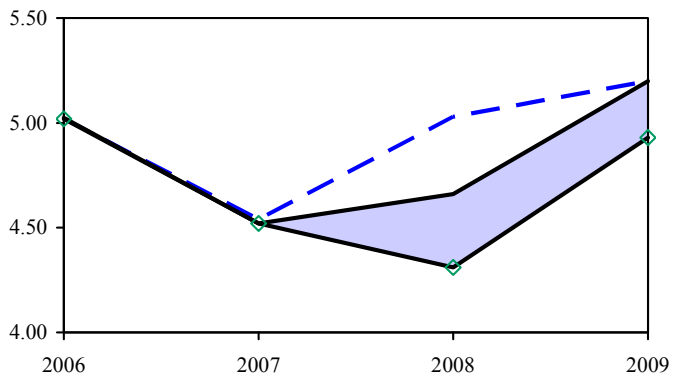

Response over marginal distribution of delta zet

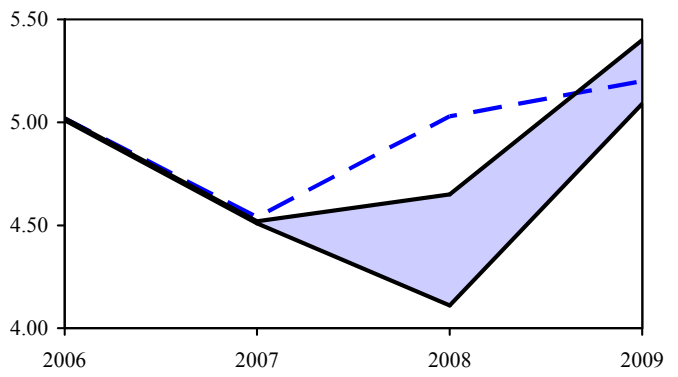

Response over marginal distribution of alpha 2

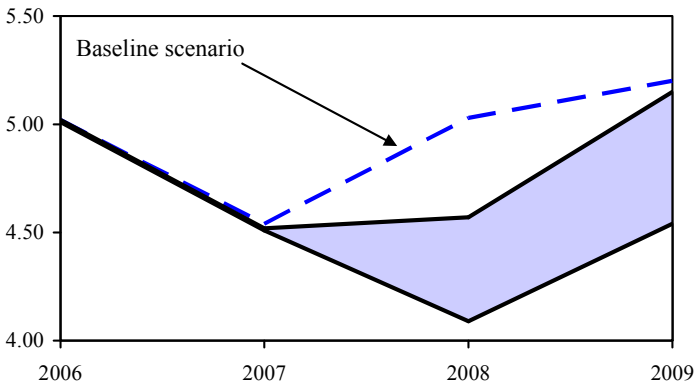

Response over marginal distribution of beta 2

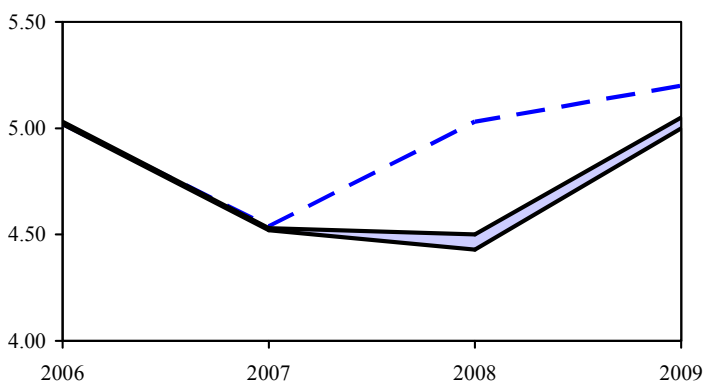

Response over marginal distribution of beta 5

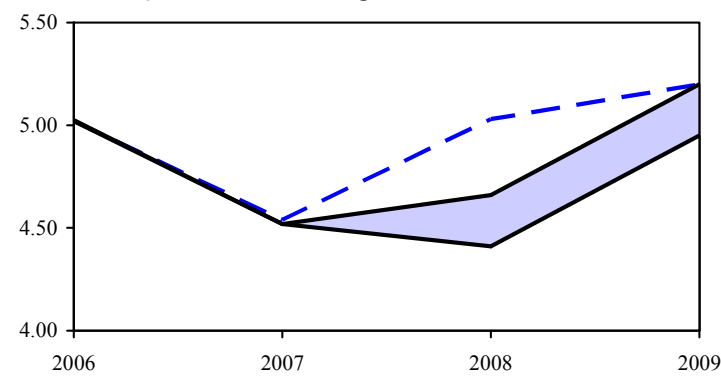

Response over marginal distribution of delta 2

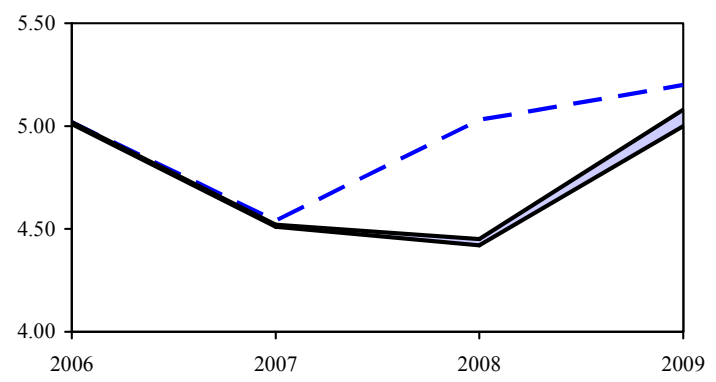

Source: Authors' calculations.

Note: The Bayesian posterior distribution is estimated jointly over all parameters. Above, we show the confidence intervals of the output response in the immediate policy response scenario over the marginal distribution of particular parameters. For example, the first panel shows the 90 percent lower and upper bound of output response as alpha 1 ranges from its 5 percent level to its 95 percent level, while keeping all other parameters at their posterior mean. 
Table 1: Model Parameter Estimation Results

\begin{tabular}{|c|c|c|c|c|c|c|}
\hline \multirow[b]{2}{*}{ Parameter } & \multicolumn{3}{|c|}{ Prior Distribution } & \multicolumn{3}{|c|}{ Posterior Distribution } \\
\hline & Type & Mean & Standard Error & $5 \%$ & Mean & $95 \%$ \\
\hline \multicolumn{7}{|l|}{ Domestic } \\
\hline$\beta_{1}$ & Beta & 0.70 & 0.20 & 0.059 & 0.210 & 0.349 \\
\hline$\beta_{2}$ & Beta & 0.10 & 0.03 & 0.052 & 0.097 & 0.144 \\
\hline$\beta_{3}$ & Gamma & 0.10 & 0.03 & 0.052 & 0.095 & 0.149 \\
\hline$\beta_{4}$ & Beta & 0.10 & 0.03 & 0.051 & 0.104 & 0.144 \\
\hline$\beta_{5}$ & Beta & 0.10 & 0.03 & 0.049 & 0.101 & 0.148 \\
\hline$\delta_{1}$ & Gamma & 0.30 & 0.06 & 0.195 & 0.260 & 0.472 \\
\hline$\delta_{2}$ & Gamma & 0.25 & 0.06 & 0.114 & 0.182 & 0.257 \\
\hline$\delta_{3}$ & Gamma & 0.30 & 0.06 & 0.200 & 0.283 & 0.365 \\
\hline$\delta_{z}$ & Beta & 0.50 & 0.10 & 0.310 & 0.411 & 0.526 \\
\hline$\alpha_{1}$ & Beta & 0.50 & 0.10 & 0.786 & 0.839 & 0.911 \\
\hline$\alpha_{2}$ & Gamma & 1.50 & 0.40 & 0.661 & 1.417 & 1.931 \\
\hline$\alpha_{3}$ & Beta & 0.50 & 0.10 & 0.170 & 0.307 & 0.482 \\
\hline \multicolumn{7}{|l|}{ Foreign } \\
\hline$\beta_{1}^{\text {us }}$ & Beta & 0.70 & 0.20 & 0.589 & 0.744 & 0.925 \\
\hline$\beta_{2}^{\text {us }}$ & Beta & 0.10 & 0.03 & 0.053 & 0.103 & 0.152 \\
\hline$\beta_{3}{ }^{\text {us }}$ & Gamma & 0.10 & 0.03 & 0.063 & 0.115 & 0.173 \\
\hline$\delta_{1}{ }^{\text {us }}$ & Beta & 0.20 & 0.06 & 0.111 & 0.204 & 0.317 \\
\hline$\delta_{2}^{\text {us }}$ & Gamma & 0.30 & 0.06 & 0.170 & 0.252 & 0.333 \\
\hline $\mathrm{a}_{1}{ }^{\text {us }}$ & Beta & 0.50 & 0.10 & 0.393 & 0.531 & 0.676 \\
\hline$\alpha_{2}^{\text {us }}$ & Gamma & 2.00 & 0.40 & 1.247 & 1.884 & 2.498 \\
\hline$\alpha_{3}^{\text {us }}$ & Beta & 0.50 & 0.10 & 0.360 & 0.511 & 0.687 \\
\hline
\end{tabular}

Sources: Bank of Thailand and Ministry of Finance. 


\section{REFERENCES}

Berg, A., P. Karam, and D. Laxton, 2006, "Practical Model-Based Monetary Policy Analysis-A How-To Guide,” IMF Working Paper 06/81 (Washington: International Monetary Fund).

Hunt, B., 2005, “Oil Price Shocks: Can They Account for the Stagflation in the 1970s?” IMF Working Paper 05/215 (Washington: International Monetary Fund).

Isard, P., and D. Laxton, 2000, "Issues Related to Inflation Targeting,” IMF Staff Country Report No. 00/106 (Washington: International Monetary Fund).

Justiniano, A., and B. Preston, 2004, "New Open Economy and Exchange Rate Pass Through: An Empirical Investigation" (unpublished; New York: Columbia University).

Lubik, T., and F. Schorfheide, 2003, "Do Central Banks Respond to Exchange Rates? A Structural Investigation," forthcoming, Journal of Monetary Economics.

Schorfheide, F., 2000, "Loss Function-Based Evaluation of DSGE Models," Journal of Applied Econometrics, Vol. 15 (November/December), pp. 645-70.

Smets, F., and R. Wouters, 2003, “An Estimated Dynamic Stochastic General Equilibrium Model of the Euro Area," Journal of the European Economic Association, Vol. 1 (September), pp. 1123-75.

Woodford, M., 2001, "Imperfect Common Knowledge and the Effects of Monetary Policy," in P. Aghion, R. Frydman, J. Stiglitz, and M. Woodford, ed. by Knowledge, Information and Expectations in Modern Macroeconomics: In Honor of Edmund S. Phelps (Princeton, New Jersey: Princeton University Press). 


\section{Global Volatility, Exchange Rates in Asia AND the Thai Foreign Exchange MARKET $^{12}$}

Against a background of higher volatility in global capital markets, this paper analyzes time series properties of foreign exchange returns and volatility for selected Asian currencies, describes key features of the Thai foreign exchange market and offers recommendations for its further development.

\section{A. Introduction}

\section{This paper examines Thai baht returns and volatility in a cross-country context.} Besides Thailand, countries included in the analysis are other ASEAN countries (Indonesia, Malaysia, and the Philippines), Korea, Singapore, Japan, China and India. ${ }^{13}$ The sample period is 2001-07. The analysis is carried out for daily bilateral U.S. dollar exchange rates. Such a cross-country analysis provides a magnitude of the transmission of shocks to Asian countries through financial markets channels, and pointers for further development of the Thai foreign exchange market where significant progress has been made over the last decade in improving the functioning of the market. Nevertheless, there remains room to further improve its efficiency through market and institutional reforms. Recommendations relate to broadening instruments for managing foreign exchange risk, easing foreign exchange regulations, and further strengthening the Bank of Thailand's (BOT) market monitoring framework.

\section{The motivation for this analysis is the higher volatility in global financial} markets since 2007 and how this has impacted currencies in the region. In the wake of the subprime crisis in the US and the unfolding global credit crunch, volatility in global

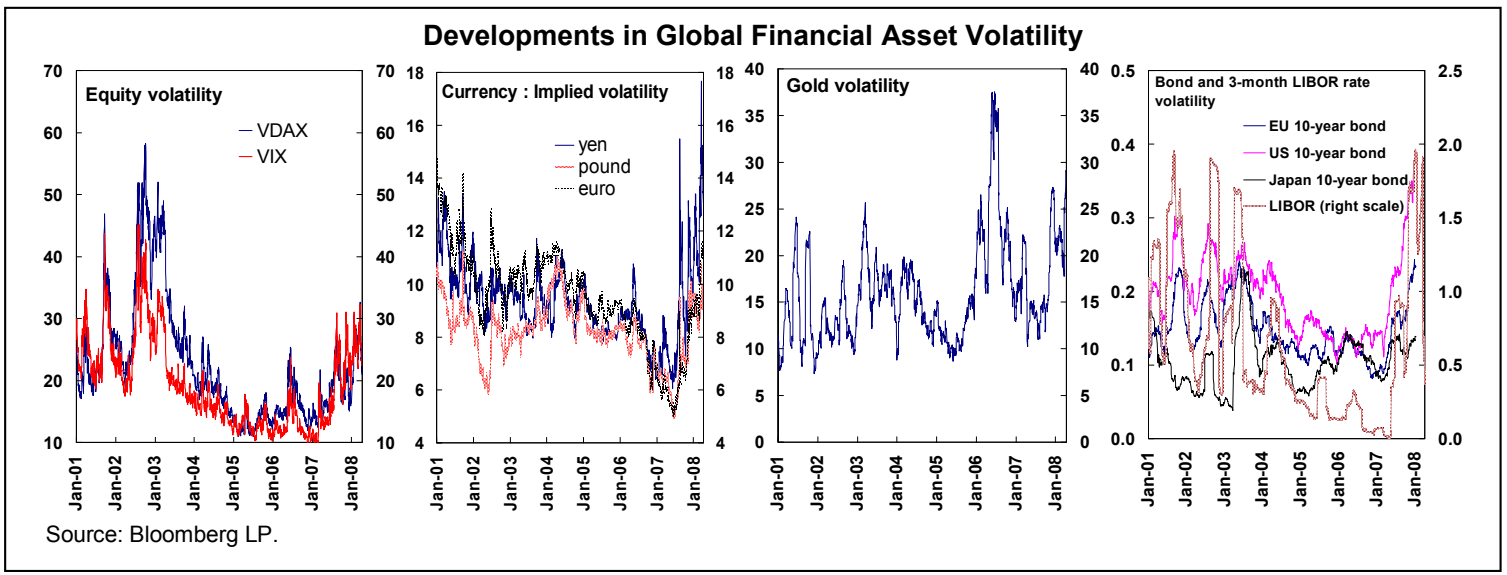

\footnotetext{
12 Prepared by Jeanne Gobat and Sanjay Kalra.

${ }^{13}$ The country mnemonics are: Thailand (THA), Indonesia (IDN), Malaysia (MYS), Philippines (PHL), Korea (KOR), Singapore (SGP), Japan (JPN), China (CHN), and India (IND).
} 
financial markets has been on a rising trend since late 2006, with a noticeable spike in mid2007. This volatility has remained elevated into 2008 , across asset classes, although at levels lower than during the peaks witnessed in 1998, and over 2001-03. ${ }^{14}$

25. The remainder of the paper is organized as follows. Section B analyzes time series properties of foreign exchange returns and volatility for Asian currencies, and outlines the main trends. Section $\mathrm{C}$ describes key features of the Thai foreign exchange market and developments. Section D offers policy recommendations for foreign exchange market development in Thailand

\section{B. Foreign Exchange Returns and Volatility: Empirical Analysis}

\section{Foreign exchange returns}

26. Over 2001-07, there were marked differences in daily exchange rate returns across Asian currencies. The average daily foreign exchange returns were stationary around $0-1 \frac{1}{2}$ basis points, with the highest returns on the Korean won and the Thai baht (Figures 1 and 2, Table 1). The largest variations were for IDN and JPN.

\section{The dependence of exchange rate returns on global volatility has been discussed} in recent studies. Cairns et. al. (2007) estimate the sensitivity of exchange rate changes to the VIX (and a composite index of global volatility) for a range of countries, controlling for changes in the yen/dollar and euro/dollar exchange rates for the sample period 2000-06. One of the conclusions is that currencies which are considered "safe havens" appreciate with an increase in global volatility, while high-yielding currencies tend to depreciate.

\section{Volatility}

\section{There was no discernible pattern in volatility at the daily and weekly}

frequencies. There were substantial differences in the magnitude and time pattern of variability across the cross section of countries, and there appears to be no clear common pattern of comovement of foreign exchange volatility with global volatility, suggesting differences in the sensitivity of country exchange rate volatility to global developments at high frequencies. The squared daily returns exhibited patterns of persistence and clustering within countries over time, common in daily asset returns (Figure 3, Table 2,). The distributions of squared returns were also markedly skewed and leptokurtic.

\footnotetext{
${ }^{14}$ The higher levels of global volatility over 2001-03 were associated first with September 2001 attacks, during June-July 2002 with geopolitical tensions and the WorldCom accounting scandal and bankruptcy, and in May 2006 with the multimarket sell-off (Cairns and others, 2007).
} 
29. Volatility patterns are more discernible at lower frequencies. Figures 4 and 5 show foreign exchange return volatilities - for periods and on a rolling basis - at the monthly (23 trading days), quarterly (65 trading days), and annual (261 trading days) frequencies. The following stylized facts emerge:

- $\quad$ There was no uniform pattern of volatility across countries. Differences across countries reflect different degrees of exchange rate flexibility, institutional differences across market structures, and market depth for the currencies. Volatility in IDN, KOR, and JPN was on average higher relative to other countries. Global as well as country-specific factors appear to have been important for explaining temporary movements in volatility. For THA, for example, volatility spiked at end-2006 related likely to the implemenation of the URR, and subsided thereafter.

- Volatility in CHN rose after the shift to some flexibility in exchange rate management in mid-2005. This happened in MYS as well, coinciding with the onset of movements in the renminbi. Other countries also witnessed temporary spikes in volatility around this time, suggesting that currencies in the region may have begun to move more closely with the renminbi than in the past. For IDN and KOR, volatility was on a declining trend. For PHL, volatility trended down until end-2004, and rose thereafter, especially in 2007. For IND, volatility was on a rising trend after 2003; it remained at a virtually unchanged level for SGP for the entire sample period. For a number of the countries, volatility levels spiked after mid2007 reflecting global developments, but then stabilized or subsided.

- $\quad$ Pairwise correlations of volatility for individual countries with global volatility and among countries varied. Contemporaneous (positive) correlation in country volatility with global volatility was high (defined as correlation greater than 0.25 ) for IDN, KOR, SGP, and JPN (Table 3). Across countries, volatility in the Thai baht moved most closely with the Korean won and the Singapore dollar. For other countries in the sample, the high correlations are highlighted in Table 3. ${ }^{15}$

30. Econometric models suggest that deeper and well-developed foreign exchange markets are conducive to lower persistence to volatility shocks. Persistence to shocks is common in

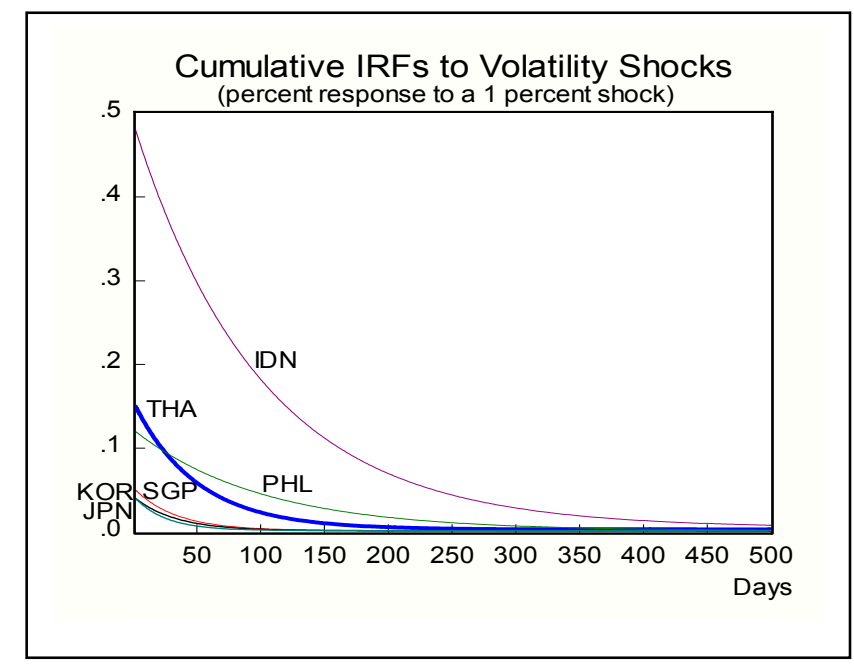

\footnotetext{
${ }^{15}$ Correlations for MYS and CHN can be ignored in this table as they include the fixed exchange rate period. For the same reason, MYS and CHN were also dropped from the model estimation.
} 
financial time series. Impulse response functions - from the error-term representation of GARCH processes estimated by staff (Appendix) - show this persistence. Among six East Asian countries, three potential groups are: Korea, Singapore, and Japan which exhibit lower persistence; Thailand and Philippines; and finally Indonesia which exhibit higher persistence to volatility shocks. The differential persistence could be due to variety of factors, including the degree of exchange rate flexibility in monetary management, institutional differences across currency markets, and the depth of the market for the currency.

\section{The Foreign Exchange Market in Thailand}

\section{Thailand has made significant progress over the last decade in enhancing the} depth and functioning of its foreign exchange market. Market turnover has doubled since 1998 with average daily turnover increasing to over US\$6 billion in April 2007. Favorable macroeconomic developments, greater financial market depth and integration, and greater flexibility in the baht have supported market activity. Other factors that may have increased foreign exchange activity are investors' increased appetite for exposure to Thailand and the region and growing global search for yield. ${ }^{16}$

\section{Cross-country comparisons also suggest that the foreign exchange market is} relatively well developed. Market turnover, for the level of gross trade in goods and services and capital flows, is above average ${ }^{17}$ Bid-ask spreads are tighter for the Thai baht compared to some regional currencies (Korean won, Indonesia rupee, Philippine peso, and Malaysian ringgit), although wider than some other, more liquid, emerging markets (e.g., Israel, Mexico, and Turkey) or financial centers (Singapore and Hong Kong). ${ }^{18}$ Average ticket size (US\$5 million) appears to be in line with most other countries.

\section{Among the key characteristics of the Thai foreign exchange market are:}

- The market is relatively well developed, in particular at the short end. The range of products includes spot, forwards, and certain derivatives (options, swaps, and interest rate swaps). Contracts for three months or less constitute the bulk of the market. Market survey data point to adequate liquidity in the spot, swap and forward market in tenors up to one year. There are no Thai baht future contracts traded, but the use of cross-currency swaps and options is growing.

\footnotetext{
${ }^{16}$ Ho and others (2005) and Gelati and Melvin (2004).

${ }^{17}$ Average daily market turnover data for April 2007 were annualized. For THA, the average daily for April approximated the actual daily average market turnover for 2007. Turnover data include the spot, forward, and swap market. Turnover can be used as indicator for assessing market liquidity, as well as bid-ask spreads and/or the average transaction size.

${ }^{18}$ Deutsche Bank, Emerging Markets Currency Handbook, 2008.
} 
- The U.S. dollar still accounts for the bulk of currency trade, similar to other regional foreign exchange markets. The dominance of the U.S. dollar in crosscurrency transactions reflects its role as the vehicle currency in the region, and is still considered the cheapest way of settling currencies in the region as market liquidity tends to be concentrated in the local currency/U.S. dollar transactions.

- $\quad$ Trading among banks accounts for the bulk of trade. Survey data suggest that interbank trading accounted for 47 percent of foreign exchange turnover, bankcustomer transactions for 29 percent, respectively, with nonresidents accounting for the remainder. Most interbank dealings are transacted on an electronic trading platform (Reuters dealing system) and over the counter. The trading, clearing and settlement system executes trades and orders on a timely and efficient basis. Banks, in particular foreign branches, actively use the foreign currency market for managing their local funding operations.

- Swap operations are the preferred funding vehicle for banks. Adequate liquidity in the swap market allows foreign banks, in particular, to run their baht funding and cash management operations through the swap market. The implied interest rates out of forward market (THB FIX) are used for pricing domestic interest rate swaps. ${ }^{19}$

34. Some recent market trends are noteworthy. Swap transactions dominated recent market turnover, while activity in the spot and forward markets declined. Swaps accounted for about two-thirds of market turnover, compared to 46 percent in 2004. While the use of forwards has increased since 1998, its demand has fallen more recently. This may reflect, among others, forward market restrictions on nonresidents since October 2003. Also, the role of nonresidents in market activity has declined over the past decade. Nonresidents' share fell from roughly 40 percent in 1998 to under 25 percent in $2007 .^{20}$ The reduced presence of nonresidents may, among others factors, reflect the impact of the capital controls introduced by the BOT. ${ }^{21}$

\footnotetext{
19 The money market cash curve is viewed as less reliable for pricing money market instruments and longer dated tradable fixed income instruments. The absence of a liquid money market cash curve does not pose a problem in itself, as baht funding operations can be carried out through foreign exchange swaps.

${ }^{20}$ Bank for International Settlements (BIS) 2007 survey data shows that cross-border trades accounted for over 60 percent of all turnover.

${ }^{21}$ In September/October 2003, the BOT restricted nonresidents' access to baht funding. A credit ceiling was set at B 50 million for lending unrelated to a verifiable business transaction. The ceiling applies to direct lending, forwards and swaps. Residents also cannot borrow more than B 50 million from nonresidents.
} 


\section{Market Development: Issues and Policy Directions}

\section{There is room to further enhance the efficiency of the Thai foreign exchange} market. Studies show that in well-functioning foreign exchange markets, exchange rates respond more effectively to market forces with durations of excess liquidity and deviations from price equilibrium less persistent. ${ }^{22}$ These markets tend to be characterized by relatively tight bid-ask spreads, lowering transaction costs; high turnover in volume and abundance in orders, minimizing price impact of individual trades; efficient trading, clearing, and settlement systems, facilitating efficient and timely execution of orders; and wide and diverse range of active market participants, ensuring that new orders flow quickly to correct order imbalances and misalignments. That is, imbalances quickly correct themselves and foreign exchange volatility reverts more quickly to levels witnessed before the shock. Reforms could further enhance the efficiency of the foreign exchange market:

- Further easing of regulatory restrictions on nonresident activity in the onshore market and on resident activity abroad. The BOT has relaxed surrender requirements, raised overall limits on outflows recently and in early 2008 removed the unremunerated reserve requirement. Nevertheless, the overall restrictiveness of the regime remains high and complex. Relaxing restrictions on inflows and outflows would enhance cross-border transactions and market turnover, lower transaction costs, expand the diversity of market participants, while allowing for more investment depth and some speculative trading, which are necessary for two-way trades and greater market liquidity.

- As Thailand moves toward the implementation of risk-based banking regulatory framework, the BOT may want to consider relaxing net open position limits (NOPs) and liquid asset ratios (LARs) for banks. ${ }^{23}$ Currently, the NOP limits are not binding and thus are not a hindrance to foreign exchange market development in Thailand. But similar initiatives have been undertaken elsewhere as a means to enhance the flexibility of liquidity management on the part of banks but also with an eye toward market development. Korea, for instance, increased limits on NOPs to 50 percent of capital while Malaysia and Singapore completely abolished NOP limits and LARs. Under this approach, banks use instead their internal models to manage liquidity and market risk (including foreign exchange), providing them with greater flexibility in managing various risk exposures while at the same time encouraging market development. Similarly, restrictions governing derivatives transactions could also be eased under a risk-based supervision model. Risk management products such as options and futures play an important role in attracting trading activities and promoting foreign exchange market

\footnotetext{
22 See Sarr and Lybek (2002) and Duttagupta and others (2004).

${ }^{23}$ The aggregate limit on NOP is set at 20 percent of capital while that on LAR is set at 6 percent. Compliance with NOP is verified on a daily basis. Banks will be moving toward Basel II at end-2008.
} 
liquidity by permitting the pooling and trading of market and credit risks. ${ }^{24}$ Of course, supervisors would have to ensure that financial institutions have adequate internal capacity and controls to manage these risks.

- Further developing deeper domestic money and bond markets. Well-functioning foreign exchange markets typically co-exist with liquid domestic money and bond markets as these domestic markets can be used to establish pricing relationships between domestic and foreign currencies at different tenors and are important for managing risk exposures. Going forward, consideration could be given to developing a market for interest rate futures and addressing the fragmentation in the government securities market and some of the shortcomings in the issuance strategy. Recent measures to promote the repo market should also help to improve conditions in the money market, as well as for bond financing and short selling.

- Streamlining documentation and reporting requirements, and moving toward a more market-friendly communication and monitoring framework. Extensive documentation and reporting requirements for foreign exchange transactions entail significant transaction and compliance costs and can be a deterrent to market entry and activity. These problems can be reduced by moving toward risk-based supervision, greater use of surveys to gather data, as well as by the BOT enhancing its market liaison as a means to gather financial market intelligence.

- Improving further the transparency of the foreign exchange market. Thailand maintains a foreign exchange transaction reporting system, according to which banks must put all cross-border transactions above a certain limit in a central computerized system that includes the data of the participants in the transaction. While this information is useful for internal analysis and understanding source of foreign exchange market pressures through transactions volume, the BOT may want to consider publishing on a regular basis aggregate foreign currency market turnover data. Greater amount of publicly available information on foreign exchange transaction would help enhance price discovery and over time be beneficial to reducing volatility.

- Enhancing the leadership role of private market organizations in market development and establishing standards. The Association Cambiste Internationale and Thailand Bond Market Association currently lack the mandate and authority to push for international standards in market practices in the local foreign exchange, money and bond markets. There is also no real market forum to discuss comprehensive market development issues. Such market forums have proven effective in other countries and central banks typically participate as observers.

\footnotetext{
${ }^{24}$ BIS reports a negative relationship between market sophistication and regulatory restrictions (Hohensee and Lee, 2006).
} 


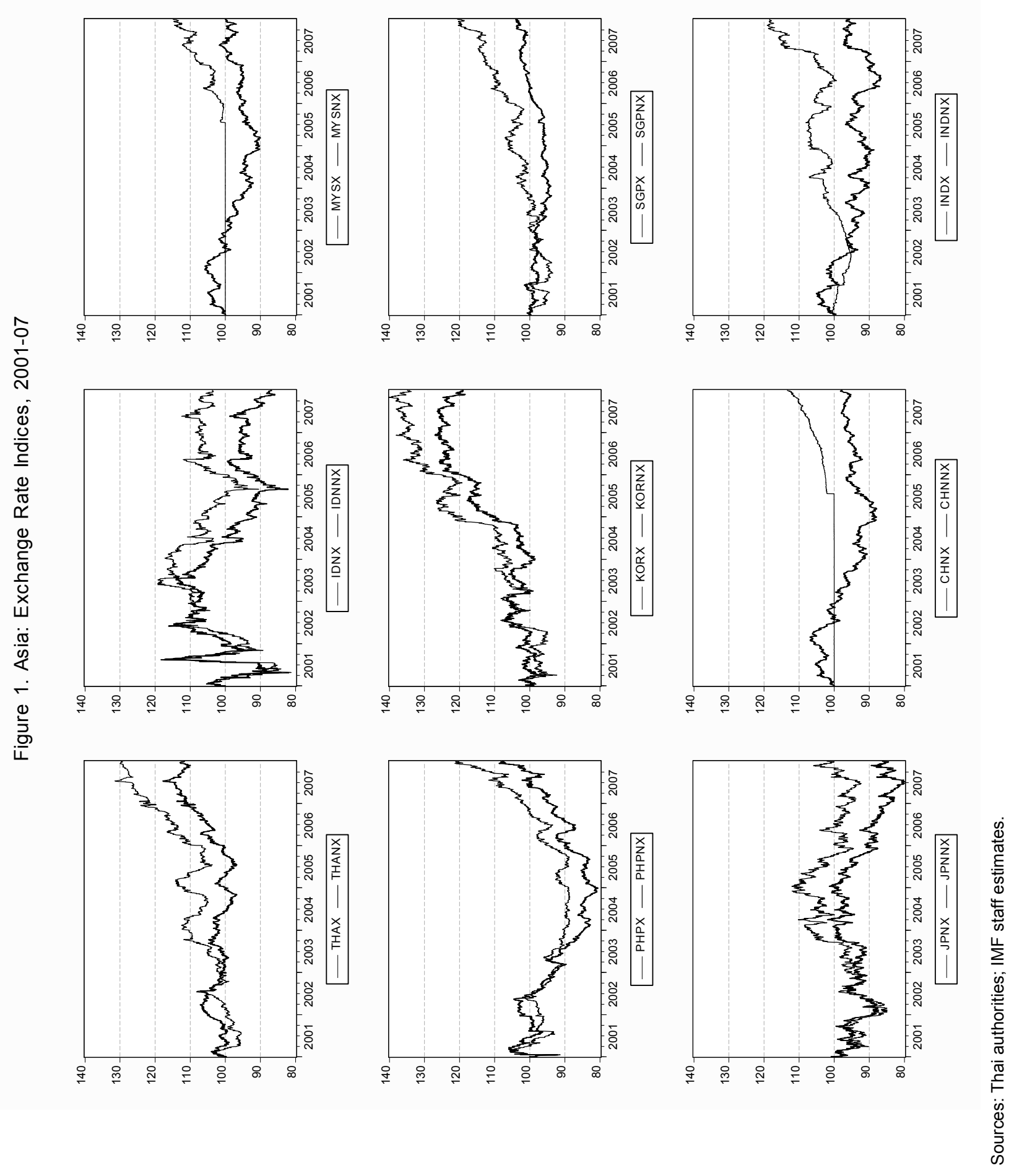




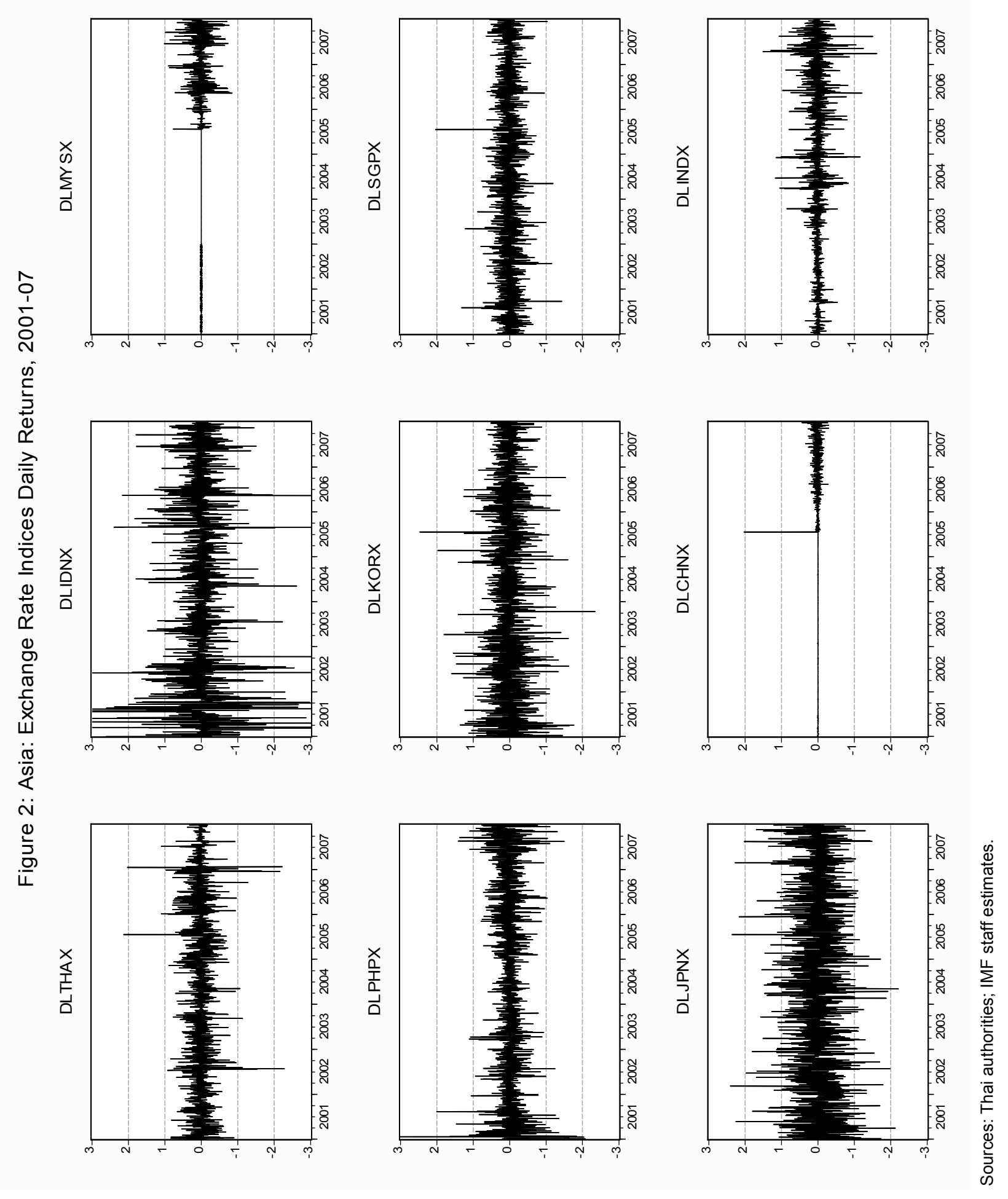




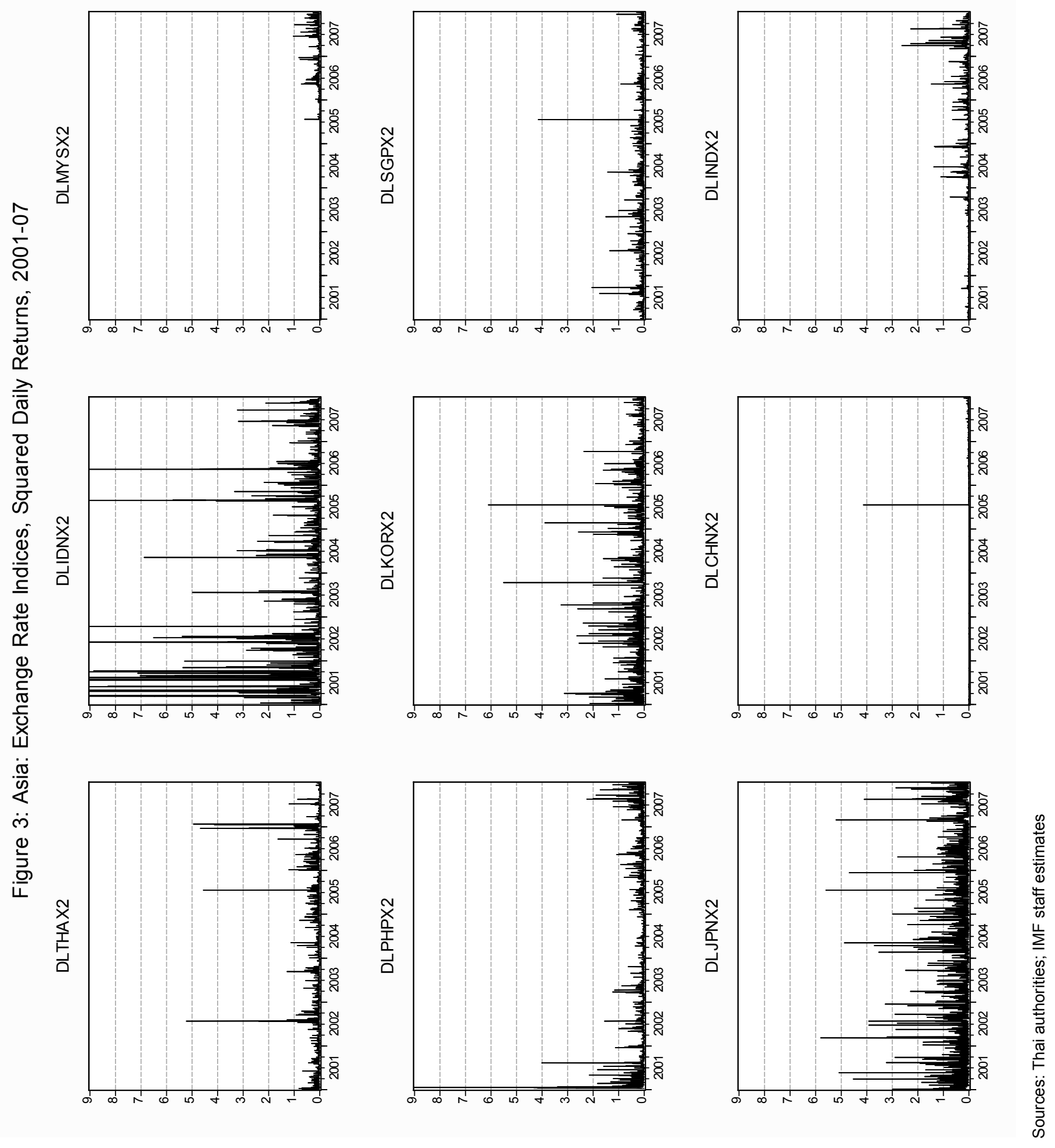




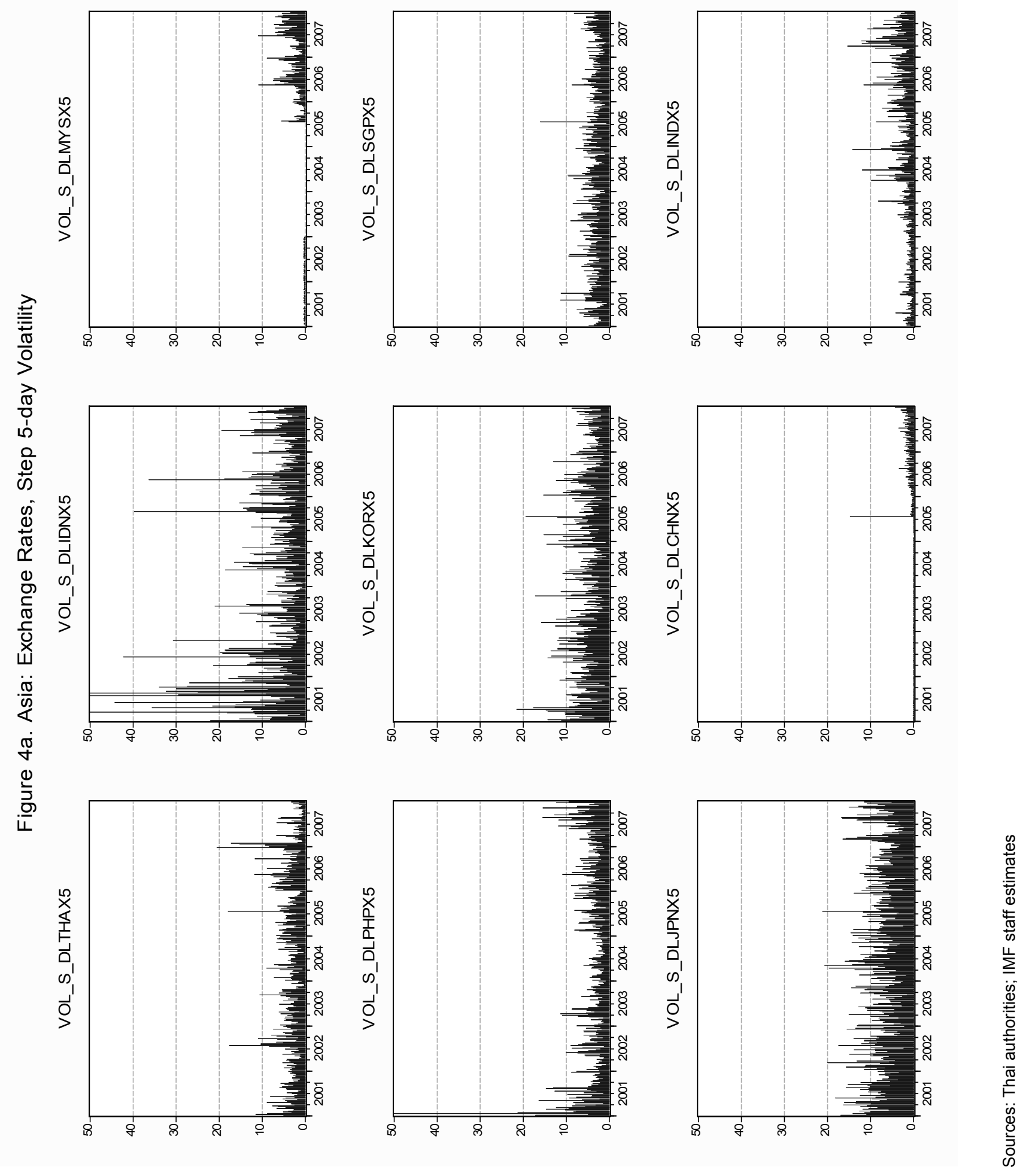




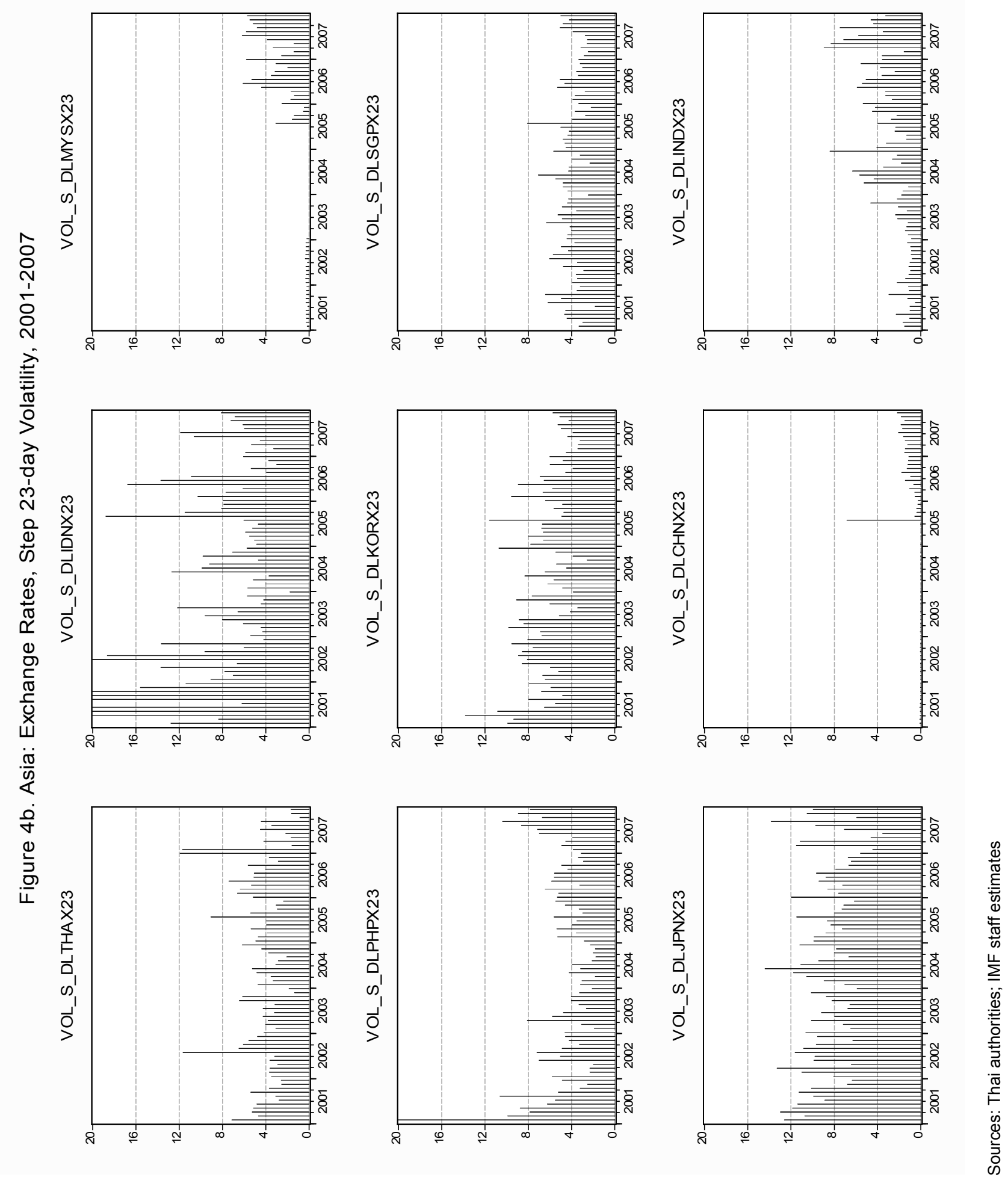




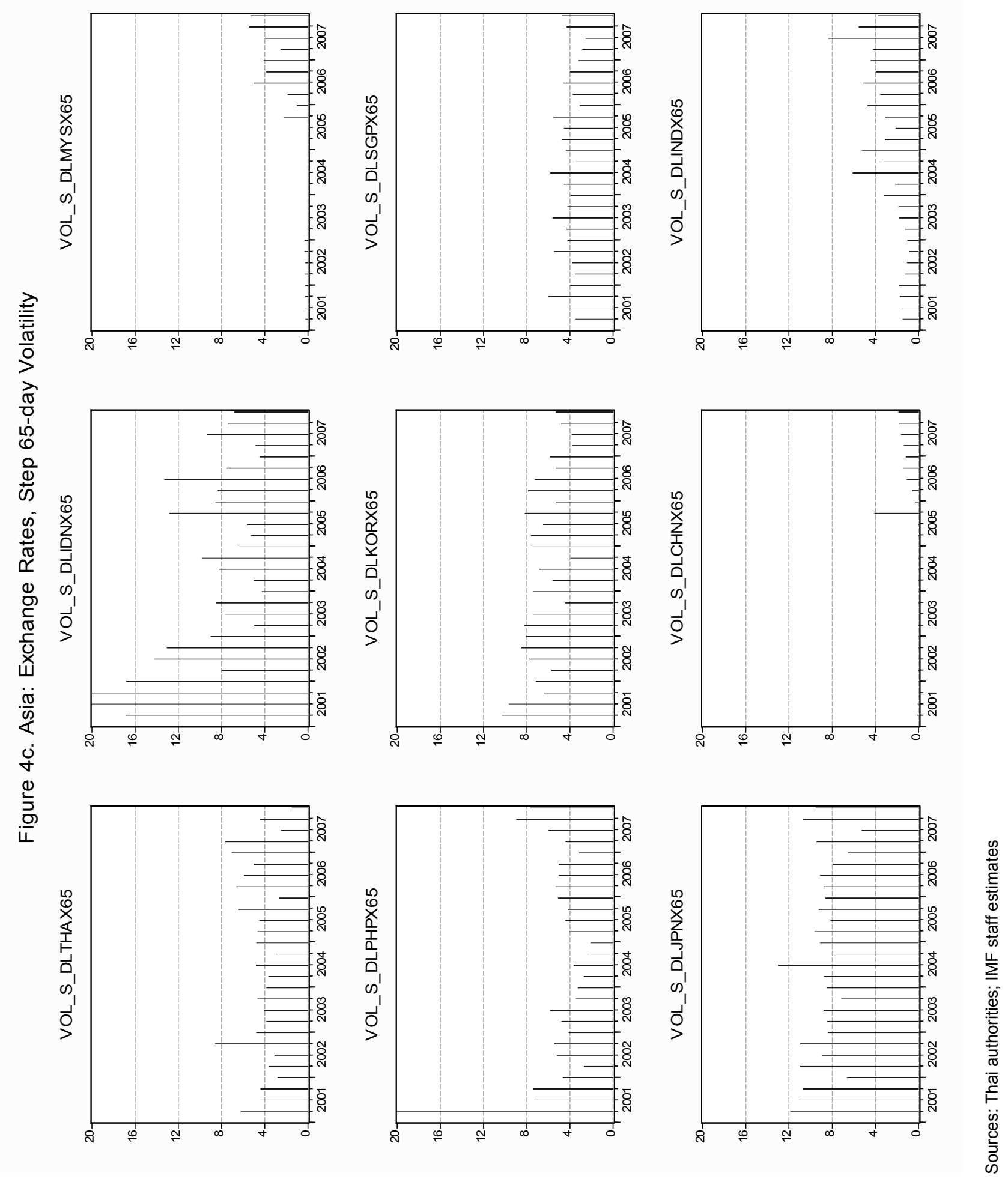




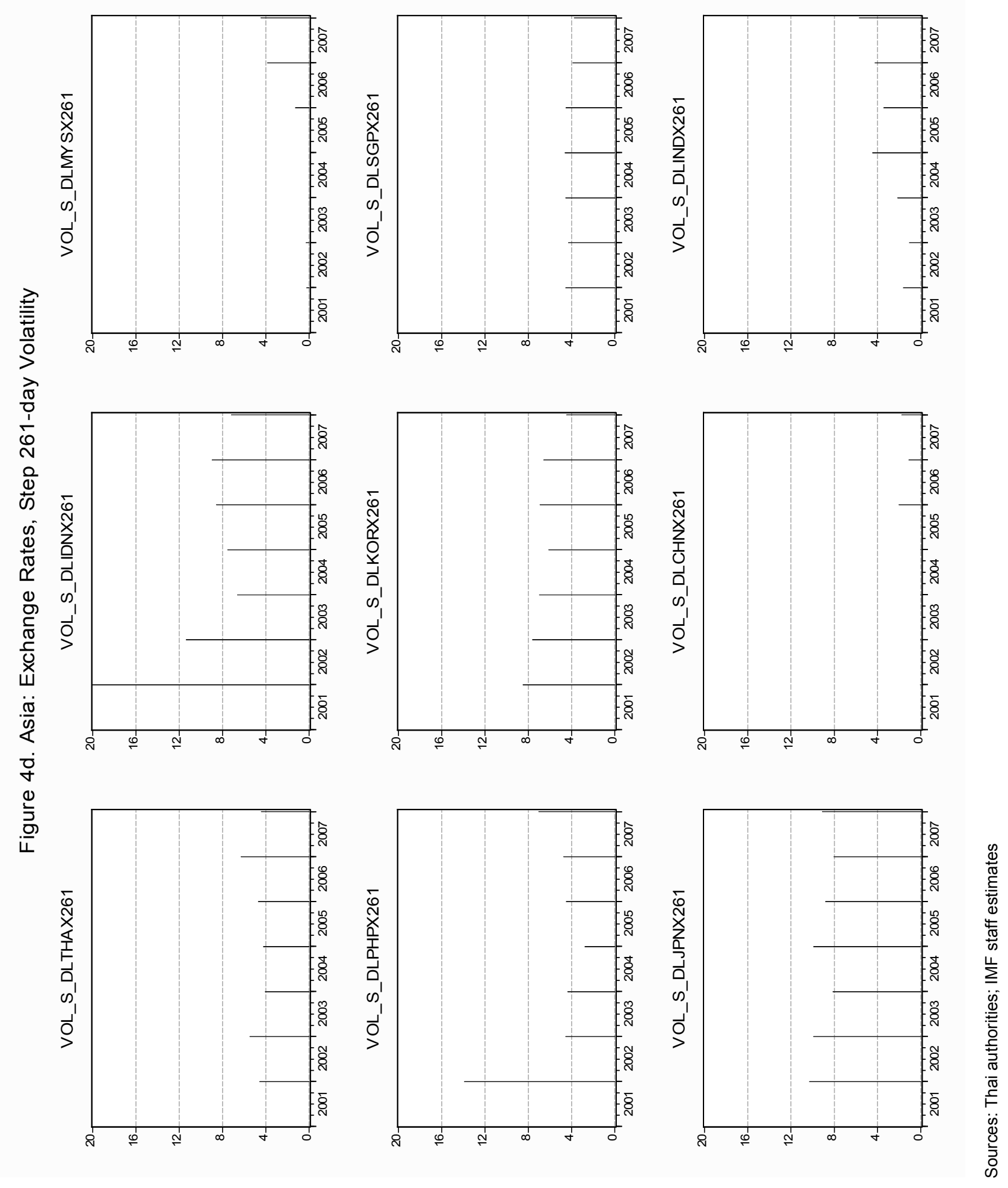




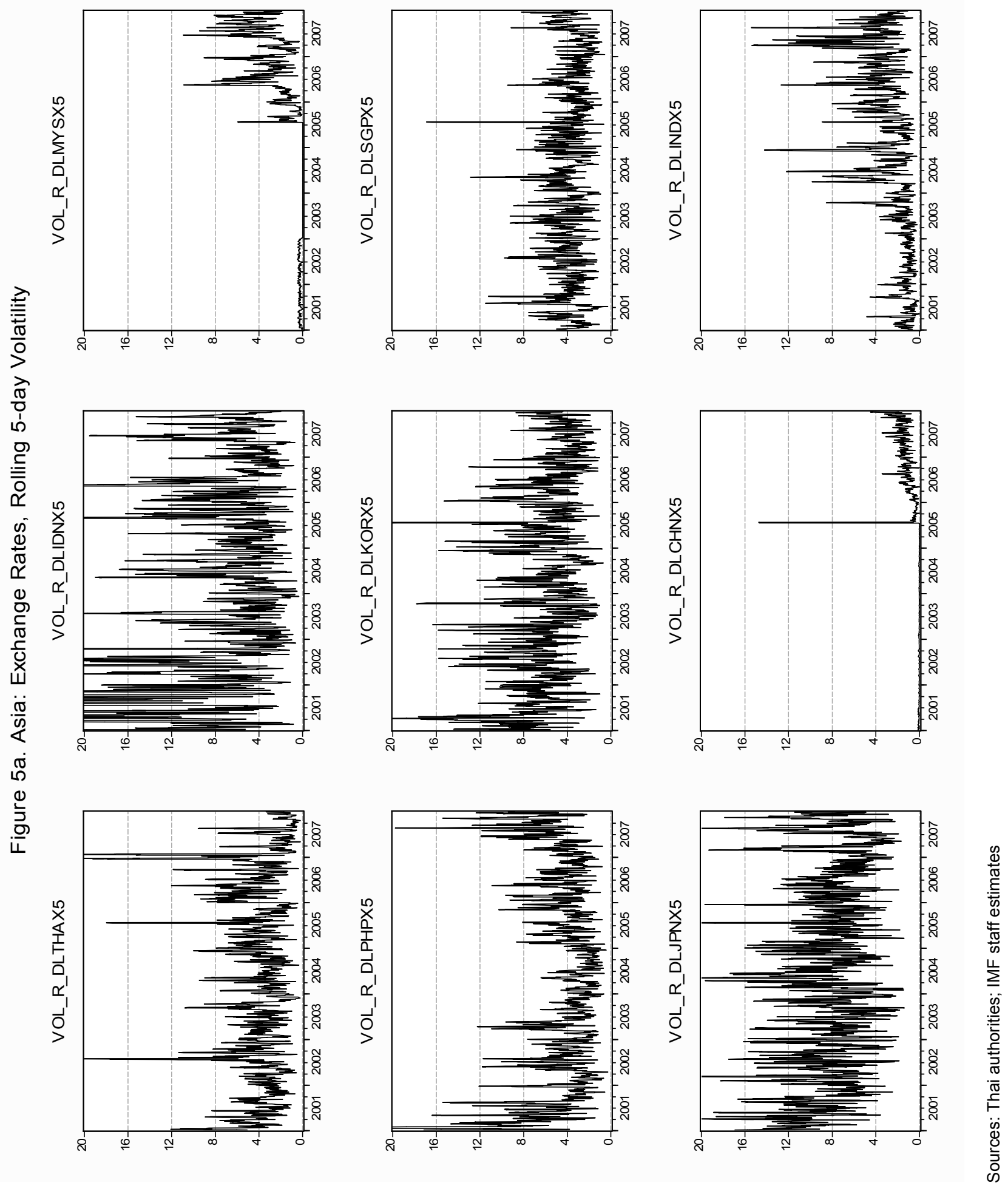




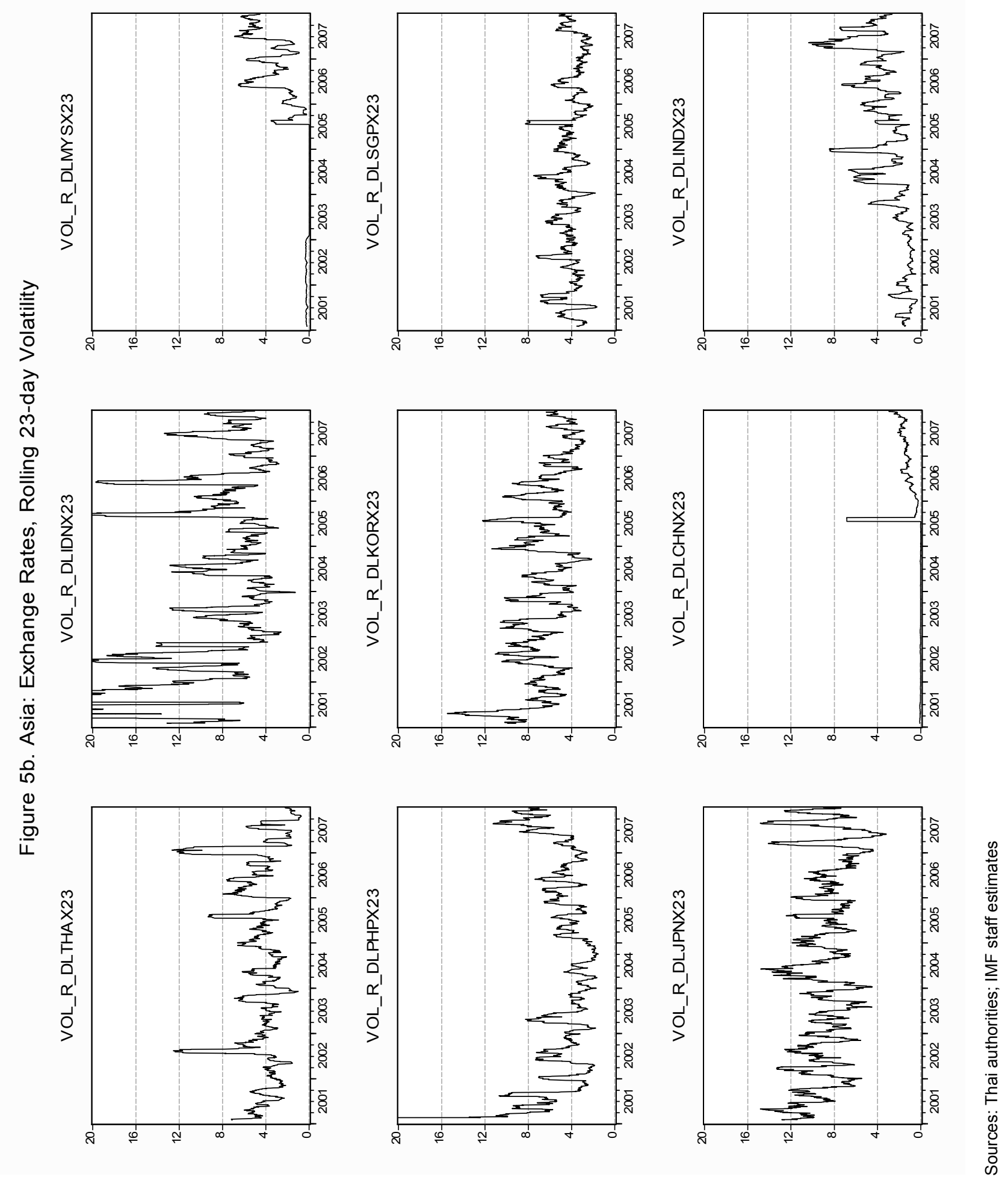




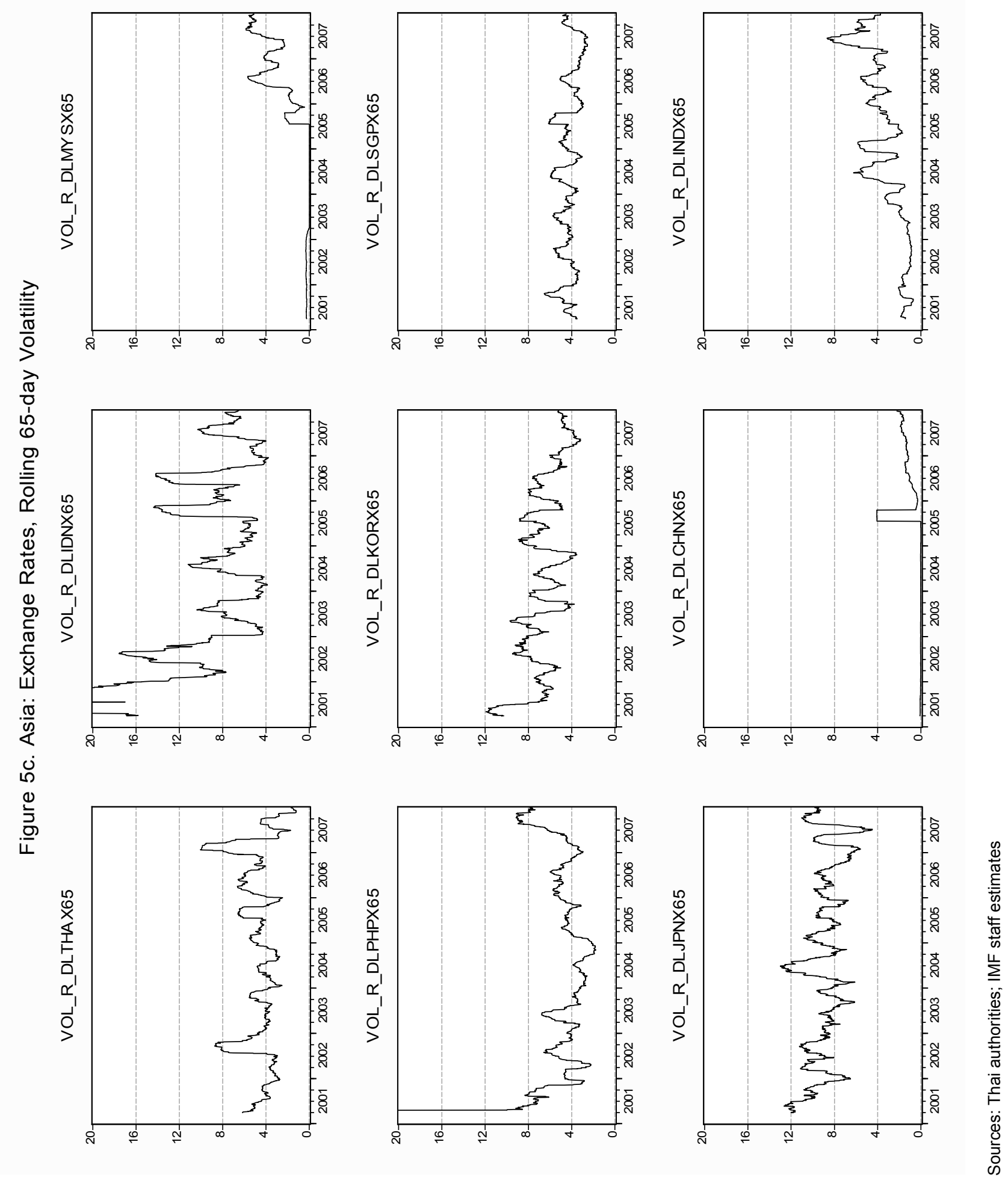




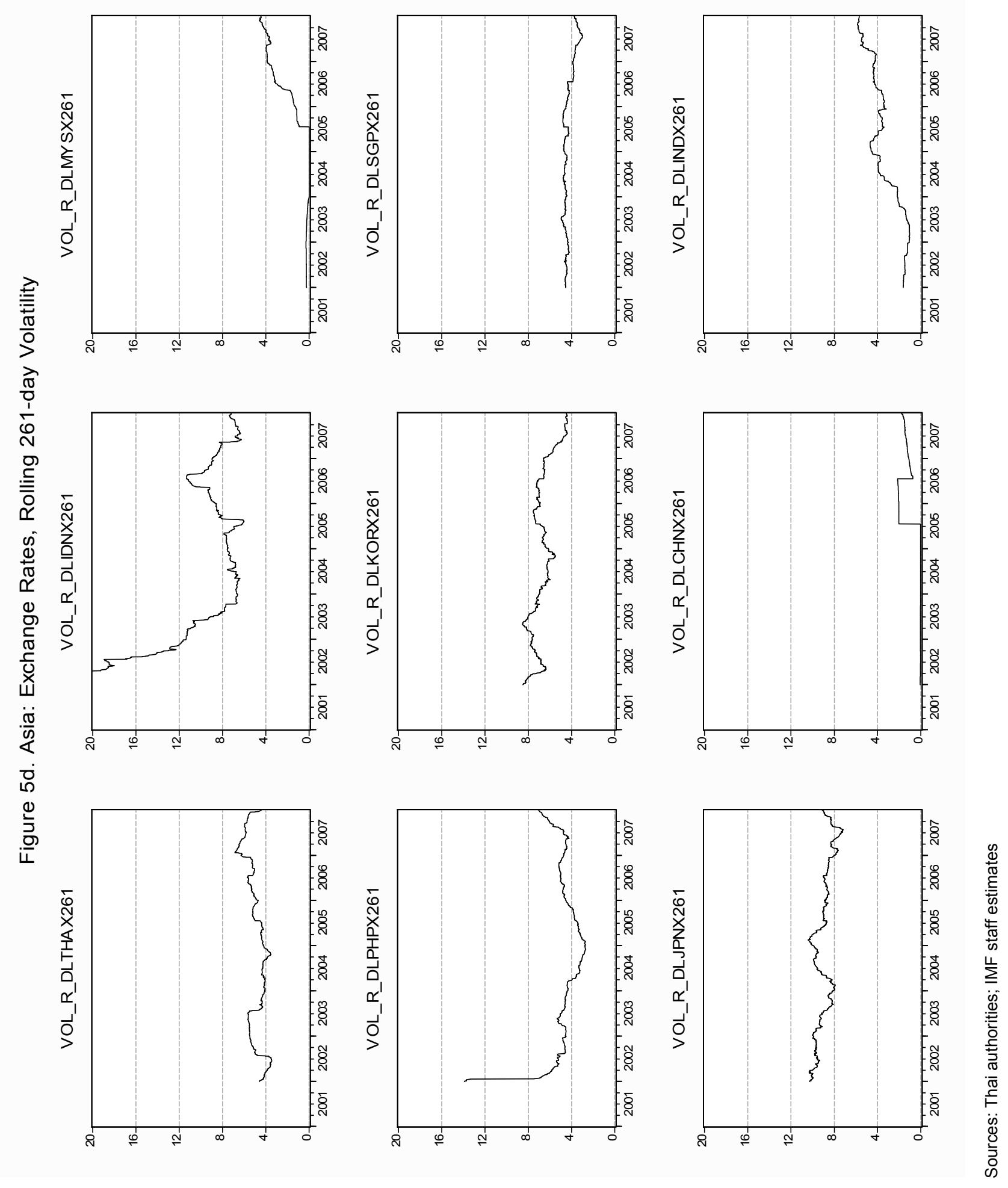


Figure 6. Size of Foreign Exchange Markets in Selected Emerging Market Countries
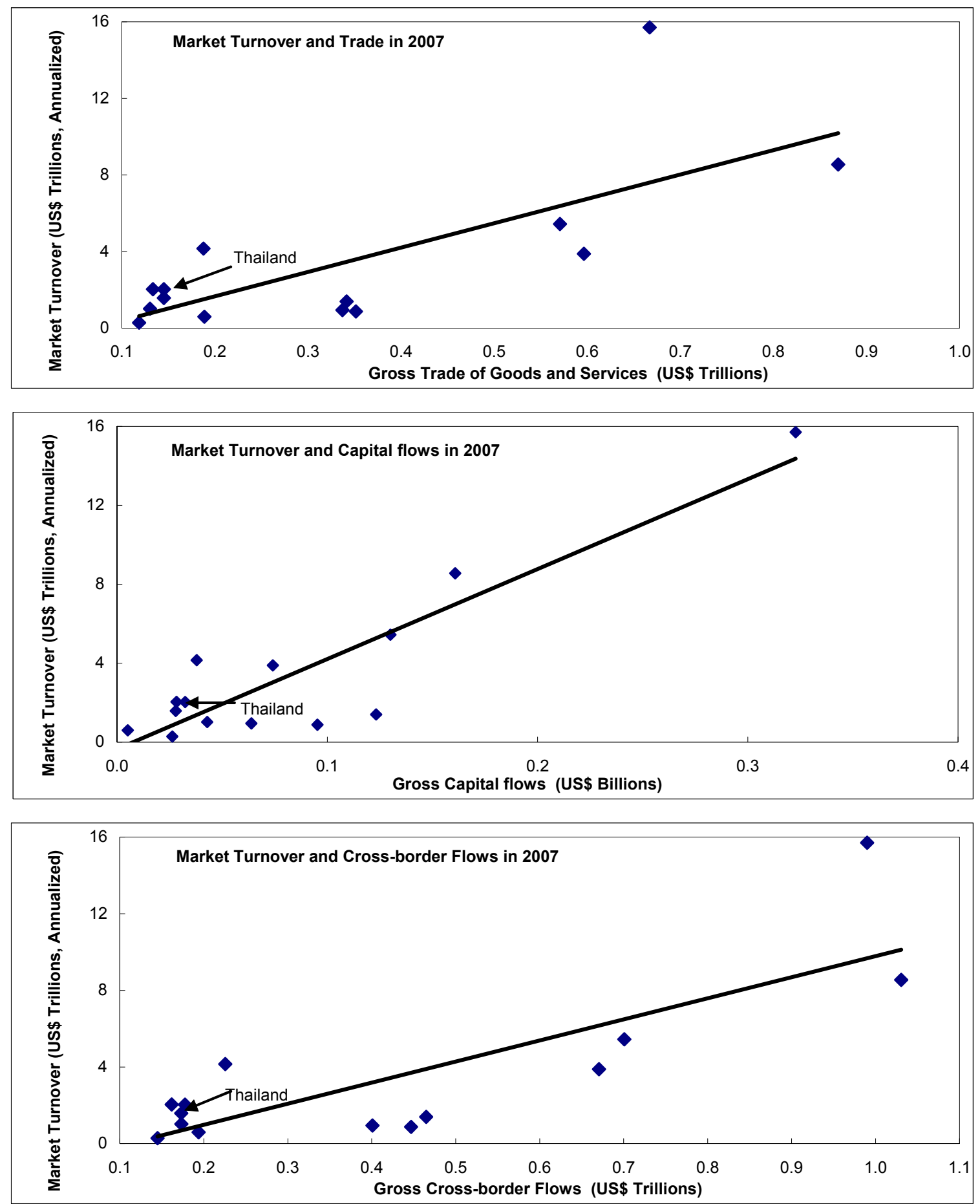

Sources: BIS, Triennial Central Bank Survey of Foreign Exchange and Derivatives Market, April 2007; CEIC Data company; and IMF staff calculations.

1/ Countries included: Argentina, Brazil, Chile, India, Indonesia, Israel, Korea, Malaysia, Mexico, Philippines, Russia, South Africa, Thailand, and Turkey. 
Table 1. Average Daily Bilateral Foreign Exchange Rate Returns, Summary Statistics

\begin{tabular}{|c|c|c|c|c|c|c|c|c|c|}
\hline & THA & IDN & MYS & $\mathrm{PHL}$ & KOR & SGP & JPN & $\mathrm{CHN}$ & $\overline{I N D}$ \\
\hline Mean & 0.014 & 0.002 & 0.008 & 0.011 & 0.016 & 0.01 & 0.001 & 0.007 & 0.009 \\
\hline Median & 0.000 & 0.000 & 0.000 & 0.000 & 0.017 & 0.013 & -0.009 & 0.000 & 0.000 \\
\hline Maximum & 2.1 & 9.0 & 1.0 & 11.1 & 2.5 & 2.0 & 2.4 & 2.0 & 1.5 \\
\hline Minimum & -2.3 & -5.9 & -0.8 & -2.1 & -2.3 & -1.4 & -2.2 & -0.3 & -1.6 \\
\hline Std. Dev. & 0.3 & 0.7 & 0.1 & 0.4 & 0.4 & 0.3 & 0.6 & 0.1 & 0.2 \\
\hline Skewness & -0.5 & 0.8 & 0.4 & 9.4 & -0.2 & 0.1 & 0.2 & 14.3 & 0.0 \\
\hline Kurtosis & 11.6 & 27.3 & 16.5 & 251.8 & 5.8 & 6.1 & 4.0 & 410.8 & 12.4 \\
\hline Jarque-Bera (x1000) & 5.7 & 45.1 & 13.9 & 4733.8 & 0.6 & 0.7 & 0.1 & 12707.6 & 6.7 \\
\hline Probability & 0.0 & 0.0 & 0.0 & 0.0 & 0.0 & 0.0 & 0.0 & 0.0 & 0.0 \\
\hline Sum & 25.9 & 3.7 & 13.9 & 19.2 & 29.9 & 18.7 & 2.1 & 12.5 & 16.8 \\
\hline Sum Sq. Dev. & 167.3 & 903.2 & 36.7 & 332.9 & 327.9 & 131.1 & 594.6 & 8.7 & 90.7 \\
\hline Observations & 1825 & 1825 & 1825 & 1825 & 1825 & 1825 & 1825 & 1825 & 1822 \\
\hline
\end{tabular}

Table 2. Volatility of Daily Forex Returns (Monthly Average), Summary Statistics

\begin{tabular}{|c|c|c|c|c|c|c|c|c|c|c|}
\hline & THA & IDN & MYS & $\mathrm{PHL}$ & KOR & SGP & JPN & $\mathrm{CHN}$ & IND & VIX \\
\hline Mean & 4.3 & 9.3 & 1.3 & 5.1 & 6.5 & 4.1 & 9.0 & 0.5 & 3.0 & 19.1 \\
\hline Median & 4.0 & 6.9 & 0.3 & 4.0 & 6.2 & 4.0 & 8.9 & 0.0 & 2.3 & 17.3 \\
\hline Maximum & 12.0 & 32.0 & 6.6 & 42.7 & 14.8 & 8.1 & 14.7 & 6.8 & 10.0 & 37.6 \\
\hline Minimum & 0.8 & 2.7 & 0.0 & 1.8 & 2.8 & 1.8 & 3.2 & 0.0 & 0.3 & 10.8 \\
\hline Std. Dev. & 2.1 & 6.3 & 1.9 & 4.6 & 2.2 & 1.2 & 2.3 & 1.0 & 2.1 & 6.9 \\
\hline Skewness & 1.4 & 1.6 & 1.5 & 6.4 & 0.8 & 0.7 & 0.2 & 3.8 & 1.2 & 0.9 \\
\hline Kurtosis & 6.3 & 5.4 & 4.0 & 52.5 & 4.0 & 3.8 & 2.7 & 23.1 & 4.2 & 2.8 \\
\hline Jarque-Bera & 67 & 58 & 36 & 9154 & 13 & 9 & 1 & 1617 & 26 & 10 \\
\hline Probability & 0.00 & 0.00 & 0.00 & 0.00 & 0.00 & 0.01 & 0.65 & 0.00 & 0.00 & 0.01 \\
\hline Sum & 364.7 & 784.4 & 105.5 & 431.5 & 544.9 & 347.1 & 755.7 & 44.2 & 251.2 & 1604.8 \\
\hline Sum Sq. Dev. & 377.5 & 3292.2 & 296.0 & 1782.7 & 414.3 & 114.2 & 447.5 & 77.5 & 363.8 & 3984.7 \\
\hline Observations & 84 & 84 & 84 & 84 & 84 & 84 & 84 & 84 & 84 & 84 \\
\hline
\end{tabular}

Table 3. Correlation between Daily Return Volatility (Monthly Average) and VIX

\begin{tabular}{l|rrrrrrrrrr}
\hline \multicolumn{1}{l|}{} & THA & IDN & MYS & PHP & KOR & SGP & JPN & CHN & IND & VIX \\
\hline THA & 1.00 & 0.06 & 0.08 & 0.14 & 0.41 & 0.28 & 0.17 & 0.13 & -0.04 & 0.01 \\
IDN & 0.06 & 1.00 & -0.08 & 0.21 & 0.30 & 0.21 & 0.21 & -0.18 & -0.25 & 0.37 \\
MYS & 0.08 & -0.08 & 1.00 & 0.12 & -0.22 & -0.07 & -0.09 & 0.68 & 0.48 & -0.25 \\
PHL & 0.14 & 0.21 & 0.12 & 1.00 & 0.28 & 0.01 & 0.28 & 0.09 & -0.05 & 0.18 \\
KOR & 0.41 & 0.30 & -0.22 & 0.28 & 1.00 & 0.43 & 0.47 & -0.07 & -0.20 & 0.37 \\
SGP & 0.28 & 0.21 & -0.07 & 0.01 & 0.43 & 1.00 & 0.47 & 0.13 & -0.02 & 0.26 \\
JPN & 0.17 & 0.21 & -0.09 & 0.28 & 0.47 & 0.47 & 1.00 & -0.04 & 0.01 & 0.28 \\
CHN & 0.13 & -0.18 & 0.68 & 0.09 & -0.07 & 0.13 & -0.04 & 1.00 & 0.37 & -0.28 \\
IND & -0.04 & -0.25 & 0.48 & -0.05 & -0.20 & -0.02 & 0.01 & 0.37 & 1.00 & -0.47 \\
VIX & 0.01 & 0.37 & -0.25 & 0.18 & 0.37 & 0.26 & 0.28 & -0.28 & -0.47 & 1.00 \\
\hline
\end{tabular}




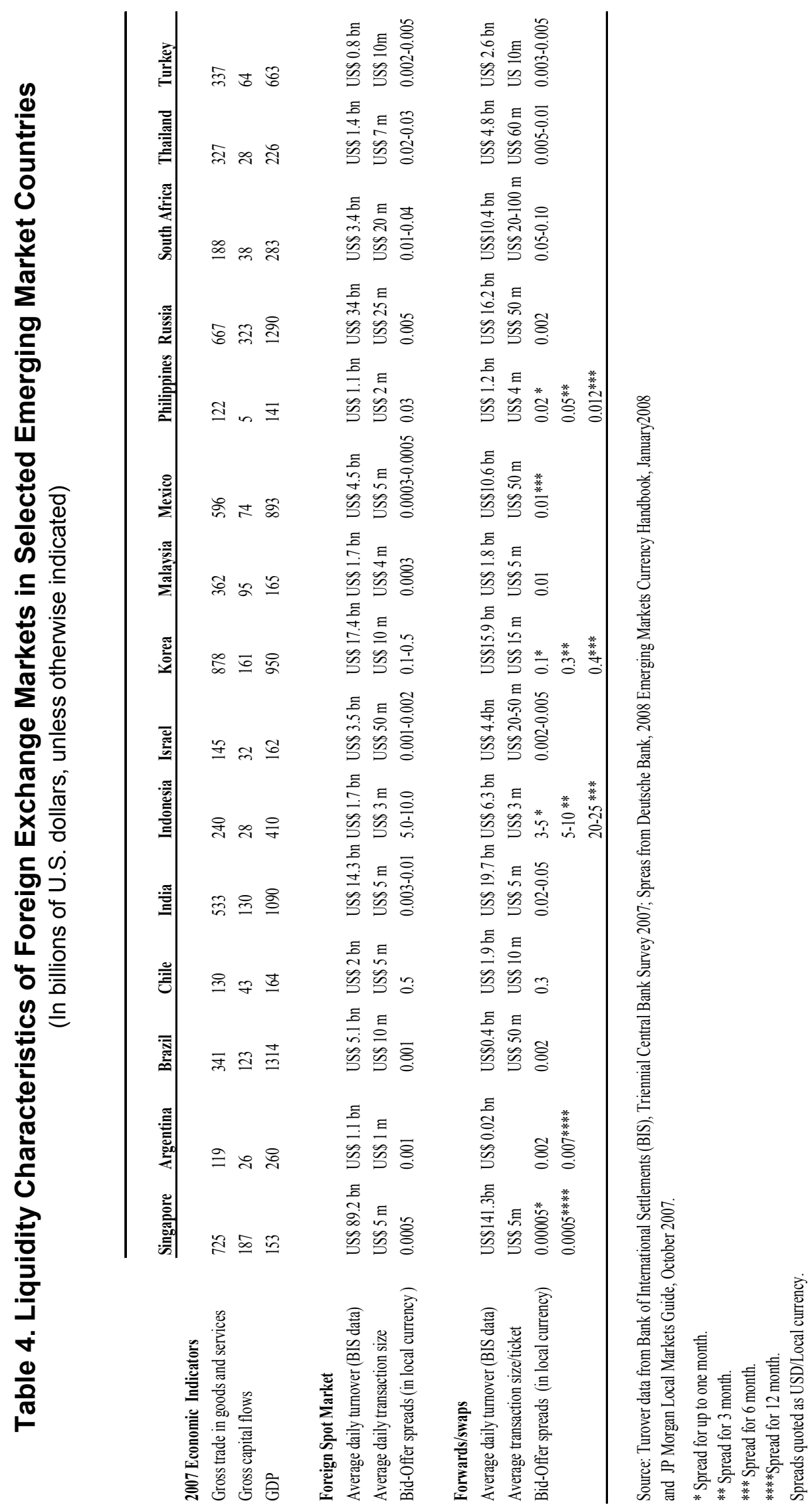




\begin{abstract}
APPENDIX
Unit root tests suggest that the exchange rate series are I(1). Autocorrelation functions for foreign exchange returns suggest an $\mathrm{AR}(1)$ formulation for returns. The squared daily returns exhibit patterns of persistence and clustering within countries over time, common in daily asset returns, implying the appropriateness of GARCH processes for modeling the returns. $\operatorname{AR}(1)-G A R C H(p, q)$ models were fitted to the daily returns, with $p=1,2$ and $q=1,2 .{ }^{25}$ The functional form of the models for the case $\operatorname{AR}(1)-\operatorname{GARCH}(1,1)$ is:

Exchange rate return:

$\mathrm{dlx}_{\mathrm{t}}=\phi_{1} \mathrm{dl}_{\mathrm{t}-1}+\varepsilon_{\mathrm{t}}$

Conditional volatility: $\quad \sigma_{\mathrm{t}}=\alpha_{0}+\alpha_{1} \varepsilon_{\mathrm{t}-1}^{2}+\beta_{1} \sigma_{\mathrm{t}-1}^{2}$

The AR(1)-GARCH(1,1) specification yielded acceptable models of returns and volatility. For THA, IDN, PHL, KOR, SGP and JPN, the coefficients of the GARCH equation were nonnegative; the coefficients on the GARCH terms were distinct and sum up to less than $1 .{ }^{26}$ With this, the conditional variance of the models is assured to be positive and the unconditional variance is well defined. With this specification, the LM test for neglected ARCH was also insignificant in all cases. The estimated models are presented below.
\end{abstract}

\title{
Asia Exchange Rates: GARCH(1,1) Models
}

Sample (adjusted): 2001-07

Included observations: 1824 after adjustments

\begin{tabular}{lrrrrrr}
\hline & THA & IDN & PHL & KOR & SGP & JPN \\
\hline dx (-1) & $0.07^{*}$ & -0.01 & -0.06 & -0.04 & 0.02 & -0.01 \\
alpha (0) & $0.00^{* *}$ & $0.07^{*}$ & $0.00^{*}$ & $0.01^{*}$ & 0.00 & $0.01^{*}$ \\
alpha (1) & $0.15^{* *}$ & $0.47^{*}$ & $0.12^{* *}$ & $0.04^{* *}$ & $0.05^{* *}$ & $0.04^{* *}$ \\
beta (1) & $0.82^{* *}$ & $0.51^{* *}$ & $0.88^{* *}$ & $0.93^{* *}$ & $0.92^{* *}$ & $0.92^{* *}$ \\
Mean dependent var & 0.02 & 0 & 0.01 & 0.02 & 0.01 & 0 \\
S.D. dependent var & 0.33 & 0.71 & 0.42 & 0.48 & 0.28 & 0.56 \\
S.E. of regression & 0.33 & 0.71 & 0.42 & 0.48 & 0.28 & 0.56 \\
Akaike info criterion & 0.42 & 1.81 & 0.35 & 1.31 & 0.24 & 1.67 \\
Schwarz criterion & 0.43 & 1.82 & 0.36 & 1.32 & 0.26 & 1.68 \\
Log likelihood & -375.7 & -1646.2 & -316.5 & -1190.9 & -218.6 & -1515.7 \\
\hline
\end{tabular}

Notes:

1/ Bollerslev-Wooldrige robust standard errors and covariance.

2/ Method: $\mathrm{ML}$ - ARCH (BHHH) - Normal distribution.

$3 /{ }^{*}$ : Significant at 10 percent; ${ }^{* *}$ : significant at 5 percent.

\footnotetext{
${ }^{25}$ Here $\mathrm{p}$ is the order of the squared error terms from the conditional mean equation (which were assumed to follow a normal distribution), and $\mathrm{q}$ is the order of the lags in conditional volatility.

${ }^{26}$ This specification is not appropriate for MYS and IND as the sum of the GARCH coefficients is greater than 1 ; for $\mathrm{CHN}$ one of the GARCH coefficients is negative.
} 


\section{REFERENCES}

Abdourahmane, S. and A. Lybek, 2002, "Measuring Liquidity in Financial Markets," IMF Working Paper 02/232 (Washington: International Monetary Fund).

Cairns, J., C. Ho, and R. McCauley, 2007, "Exchange Rate and Global Volatility: Implications for Asia-Pacific Currencies," BIS Quarterly Review (March).

Deutsche Bank, 2008, Emergency Markets Currency Handbook, 2008 (London: Global Markets Research (January 9).

Duttagupta, R., G. Fernandez, and C. Karacadag, 2004, From Fixed to Float: Operational Aspects of Moving Toward Exchange Rate Flexibility," IMF Working Paper 04/126 (Washington: International Monetary Fund).

Gelati and Melvin, 2004, "Why has Forex Trading Surged? Explaining the 2004 Triennial Survey," BIS Quarterly Review (December).

Ho, C., G. Ma, and R. McCauley, 2005, “Trading Asian Currencies,” BIS Quarterly Review (March).

Hohensee, M. and K. Lee, 2006, “A Survey on Hedging Markets in Asia: a Description of Asian Derivatives Markets and a Practical Perspective,” BIS Papers No. 30.

Sarr, Abdourahmane and Tonny Lybek, 2002, "Measuring Liquidity in Financial Markets," IMF Working Paper 02/232 (Washington: International Monetary Fund). 